\title{
Intestinal osmoregulatory mechanisms differ in Mediterranean and Atlantic European sea bass: A focus on hypersalinity
}

\author{
Cao Quanquan ${ }^{1}$, Blondeau-Bidet Eva ${ }^{1}$, Lorin-Nebel Catherine 1, ${ }^{*}$
}

${ }^{1}$ Univ Montpellier, MARBEC (CNRS, IFREMER, IRD, UM), 34095 Montpellier, France

* Corresponding author : Quanquan Cao, email address : catherine.lorin@umontpellier.fr

\begin{abstract}
:
European sea bass (Dicentrarchus labrax) migrate towards habitats where salinity can reach levels over $60 \%$, notably in Mediterranean lagoons. D. labrax are genetically subdivided in Atlantic and Mediterranean lineages and have evolved in slightly different salinities. We compared Atlantic and WestMediterranean populations regarding their capacity to tolerate hypersalinity with a focus on the involvement of the intestine in solute-driven water reabsorption. Fish were analyzed following a two-week transfer from seawater (SW, 36\%) to either SW or hypersaline water (HW, 55\%o). Differences among lineages were observed in posterior intestines of fish maintained in SW regarding NKA activities and mRNA expressions of nkaa1a, aqp8b, aqp1a and aqp1b with systematic higher levels in Mediterranean sea bass. High salinity transfer triggered similar responses in both lineages but at different magnitudes which may indicate slight different physiological strategies between lineages. High salinity transfer did not significantly affect the phenotypic traits measured in the anterior intestine. In the posterior intestine however, the size of enterocytes and NKA activity were higher in HW compared to SW. In this tissue, nkaa1a, nkcc2, aqp8ab and aqp8aa mRNA levels were higher in HW compared to SW as well as relative protein expression of AQP8ab. For aqp1a, 1b, 8aa and 8b, an opposite trend was observed. The subapical localization of AQP8ab in enterocytes suggests its role in transepithelial water reabsorption. Strong apical NKCC2/NCC staining indicates an increased $\mathrm{Na}+$ and $\mathrm{Cl}$ - reuptake by enterocytes which could contribute to solute-coupled water reuptake in cells where AQP8ab is expressed.
\end{abstract}




\section{Graphical abstract}

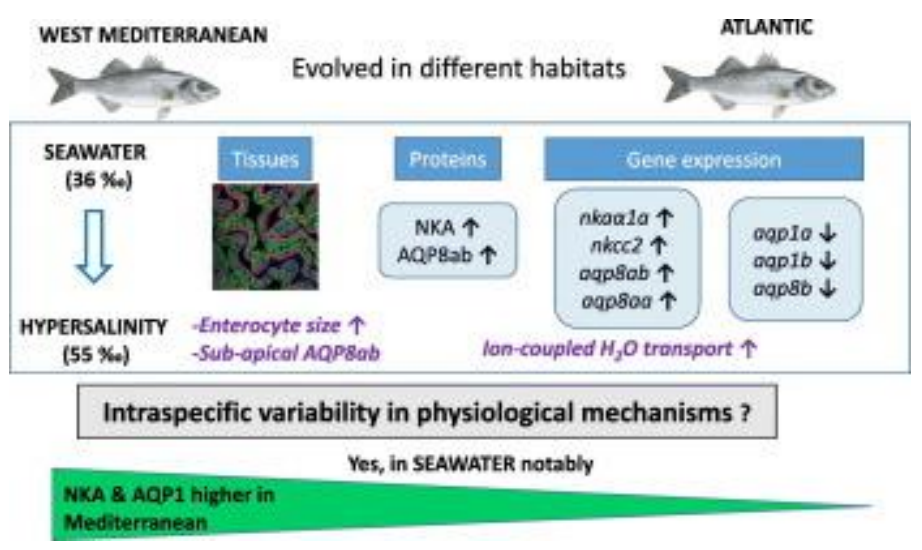

\section{Highlights}

D. labrax successfully responds to hypersalinity at the posterior intestinal level. Intestinal aquaporin $8 \mathrm{ab}$ and 8aa are overexpressed in response to hypersalinity. Solute-coupled ion transport is characterized at posterior intestinal level. Intraspecific differences were measured between Atlantic and Mediterranean D. labrax.

Keywords : hypersalinity, intestine, Dicentrarchus labrax, intraspecific comparison, osmoregulation, water transport 


\section{Introduction}

Hypersaline environments represent important osmotic and ionic challenges for teleost fish and most teleost species do not tolerate salinities over $50 \%$ (Gonzales., 2012). The Mediterranean Sea is becoming warmer and saltier since the 1960s (Borghini et al., 2014) and is now considered as a climate change hotspot. Climate-induced salinity changes can cause seasonal hypersalinity in lagoons during dry and hot summers эs frequently observed in the Mediterranean area (Largier et al., 1997). Climate change- elat d effects threaten species worldwide and within-species populations may respond dife. ${ }^{a n^{*}}$ y to climate-induced stress due to local genetic adaptation or phenotypic plasti-ty, particularly in areas with steep environmental gradients (Kinnby et al., 2020). $\mathrm{Ev}^{1} \mathrm{O}^{+}$,ean sea bass are among the most important species for aquaculture production in Euror $\mathrm{e}_{\text {, Va. }}$ teputte et al., 2019). They distribute along the coasts of the North-Eastern Atlantic Oceaı and Mediterranean and Black Sea. In some Mediterranean lagoons, where $D . \quad a^{l}, r_{1} \ldots$ are found from spring to autumn, salinities are fluctuating and can reach values au to $60 \%$ in the summer (Dufour et al., 2009). In some coastal lagoons and saltpans of the Atla tic ocean, the salinity can also reach levels higher than $36 \%$ (Newton and Mudge ? $\iota^{2}$ ) out salinity does not reach as high levels than in Mediterranean lagoons. European sea bass have been genetically subdivided into two different genetic lineages, a North-Atlantic lineage and a Mediterranean lineage subdivided into different populations (Allegrucci et al., 1997; Caccone et al., 1997; Naciri et al., 1999; Vandeputte et al., 2019). Duranton et al. (2018) estimated that Atlantic and Mediterranean D. labrax lineages have started to diverge at around 300,000 years before present. Strongly euryhaline, the European sea bass is therefore an interesting model to study osmoregulation in extreme salinities and to compare intraspecific differences in underlying mechanisms, as wild populations from Atlantic and 
Mediterranean origin have evolved in different habitats which could lead to differential acclimation and adaptive mechanisms (Lemaire et al., 2005). We therefore expect differences in their capacity to tolerate extreme salinities.

Fish intestine is a complex organ with multiple physiological functions (Schauer et al., 2018). Besides its main functions in digesting and absorbing nutrients, fish intestine is critical for the regulation of hydromineral balance (Wood and Bucking, 2011). Marine teleosts passively lose water and gain salts in seawater and hypersaline water. To baıt dehydration, fish need to compensate water loss by drinking and absorbing water via th os a rilageal-gastrointestinal (EGI) tract (Li et al., 2014, Schauer et al., 2018).

The esophagus is involved in passive desalination witı uns entering the blood system through diffusion (Grosell 2010). The intestinal fluid is i r to ic and becomes slightly hypo-osmotic to the blood due to the active pumping of io $-\mathrm{b}$, the $\mathrm{Na}^{+} / \mathrm{K}^{+}$-ATPase (NKA) (Madsen et al., 2014) linked to apical $\mathrm{NaCl}$ uptake creating an olectrogenic gradient which drives water reuptake from the mucosa to the serosa (Musch et ^1., 1r 82, Grosell 2011, Carvalho et al., 2012, Gregório et al., 2013). As a primary driving fol e for water transport, NKA activity reflects the osmoregulatory status of fish (Sardella e $e^{t}$ ๆ., 2.009) and its increase at the intestinal level following salinity change can be interpreter as an increased involvement in the regulation of hydromineral balance (Sundell and Sundh, 2012). An increase in hypersaline water (HW) versus seawater (SW) was observed in the activity of intestinal NKA in the spotted green puffer fish (Tetraodon nigroviridis) (Bagherie-Lachidan et al., 2008), in posterior intestine of striped eel catfish (Plotosidae catfishes) (Ruiz-Jarabo et al., 2016) and in anterior intestine of gulf toadfish (Opsanus beta) (Guffey et al., 2011). NKCC2 is primarily responsible for apical $\mathrm{Na}^{+}$and $\mathrm{Cl}^{-}$ uptake required for solute coupled water reuptake across the intestine (Grosell 2011). nkcc2 
mRNA expression was higher in HW (55\%) than in SW (35\%) in the anterior intestine of sea bream (Sparus aurata) (Gregório et al. 2013). Localized in the apical brush border, a more intense staining was observed for NKCC2 in enterocytes of Mozambique tilapia (Oreochromis mossambicus) following three weeks of acclimation to hypersaline media (70 \%o) ( $\mathrm{Li}$ et al. 2014).

Water absorption occurs mainly through solution-coupled water reuptake through the intestinal epithelium, which moves large amounts of water from the lumen iv the blood (Skadhauge 1974, Genz et al., 2011). In the seawater-acclimated Atlantic salmor $\sim \eta_{\text {L.' ' }}$ rown trout (Salmo trutta L.), the increased drinking rate was followed by an increas $\gamma$ fluid absorption by the posterior intestine (Veillette et al., 1993; Nielsen et al., 1999). A, taporins (AQPs) are membrane water channels involved in whole-body and cellular wat. $\mathrm{hr}$ meostasis and major sites for transcellular water uptake (Musch et al., 1982; Grosell '0r s; Wood and Grosell 2012). Among multiple AQP isoforms and paralogs, $\mathrm{AQP1a}, \mathrm{AQP} \mathrm{a}^{h}$ and $\mathrm{AQP} 10 \mathrm{a}$ have been shown to be expressed in intestinal enterocytes (Madsen et al., 2011; Engelund et al., 2013; Madsen et al., 2014). Aquaporin 1 specifically transp rts water and has two paralogs in fish (AQP1a and AQP1b) (Tingaud-Sequeira et al.. $\overbrace{}^{\mathrm{Q}}$. Several studies refer to their expression in seawater and/or freshwater media but on: tew address AQP1 involvement in hypersaline media. The increased expression of aqp 8 mRNAs following FW to $\mathrm{SW}$ acclimation suggested that AQP8 is involved in water reuptake at intestinal level in Atlantic salmon (Tipsmark et al., 2010) and Japanese eel (Anguilla japonica) (Kim et al. 2010). AQP8 is subdivided into AQP8aa, AQP8ab and AQP8b (Tingaud-Sequeira et al., 2010). In Atlantic salmon intestine, AQP8aa is restricted to a subapical area whereas AQP8ab is localized at the apical membrane and extends to the lateral membrane (Madsen et al., 2011, Engelund et al., 2013). AQP8ab is considered as the main AQP8 paralog 
participating in water absorption across the intestine of the SW-acclimated salmon whereas AQP8aa may be concerned with maintaining fluid homeostasis in intracellular compartments (Engelund et al., 2013). Transmission electron microscopy has confirmed the presence of AQP8ab at the brush border membrane of enterocytes in rainbow trout (Oncorhynchus mykiss) (Madsen et al., 2015). AQP10 has two paralogs, AQP10a and AQP10b (Santos et al., 2004; Kim et al. 2010; Tipsmark et al., 2010). AQP10a has substantial mRNA levels in the whole intestine of both freshwater and seawater-acclimated Japanese eels (Kim et ai 2010). In Atlantic salmon, intestinal aqp $10 b$ mRNA expression increased when salmone ${ }^{*} c_{2}:$ ansferred from fresh water to seawater (Tipsmark et al., 2010). In European eel anc sea bream, aqp10b transcript levels were unresponsive to salinity changes (Santos et al., 20(si iartinez et al., 2005) clearly showing species-specific features.

To respond to hypersaline salinity e. irr nments, D. labrax juveniles increase their number of branchial ionocytes (Varsamos et al., 2002), adjust their renal glomerular size (Cao et al., 2021) and increase drinking rate ('ar anos et al., 2004). We address the question of how $D$. labrax respond to hypersalinity at tıe intestine level as a key organ involved in solute-linked water reuptake and whethar $\ddot{a}$ : frerent genetic lineages respond the same way or not. Thus, the objectives of this study are 1) to quantify mRNA expression of critical ion transporters and specific activity of intestinal NKA; 2) to quantify expression of selected aquaporins; 3) to localize NKA, NKCC2/NCC and AQP8ab in D. labrax intestine. These analyses will be performed on European sea bass from West Mediterranean (M) and Atlantic (A) origin acclimated to seawater (MSW, ASW, $36 \%$ ), or hypersaline water (MHW, AHW, $55 \%$ ) for two weeks. This study aims to a better understanding of water uptake pathways in D. labrax lineages 
exposed to high salinities with a focus on the intestine and investigates physiological differences between $D$. labrax with a different evolutionary history.

\section{Materials and methods}

2.1 Fish experimentations and sampling

European sea bass D. labrax were collected from West Mediterranean and Atlantic lineages at the Ifremer Station (Palavas-les-Flots, Hérault, France). Sea bass ‘"om both lineages spawned and were reared at the Ifremer Station and were then brov ${ }_{0}^{\text {hht }}:=$ Montpellier University and maintained for a week at $36 \%$ in $3500 \mathrm{~L}$ tanks, at $70{ }^{\circ} \mathrm{C}$ and a constant photoperiod $(12 \mathrm{hL} / 12 \mathrm{hD})$. The tanks contained natural seawater from "ie Mediterranean Sea diluted with tap water. Then fish were transferred to smaller $2 x<$ anks containing either hypersaline water (HW: $55 \%$ ) or seawater (SW: $36 \%$ ). $\mathrm{H}_{。}$ 'ne saline water was made by adding sea salt (Instant Ocean, Blacksburg, USA) to seawater. $\Gamma^{*}$ sh were maintained at this salinity for two weeks until sampling. In this study, four crndi ir as were compared: West Mediterranean D. labrax maintained at $36 \%$ (MSW) anc $55 \%$ (MHW) as well as North Atlantic D. labrax maintained at $36 \%(\mathrm{AMW})$ and $55 \%,\left(\mathrm{~V}_{\mathrm{W}} \mathrm{W}\right)$. Water was mechanically/biologically aerated and filtered (Eheim System, Lens, F. s-de-Calais, France). Oxygen levels, nitrogen levels, temperature and salinity were regularly measured and adjusted. A siphon tube was used to daily remove $10 \%$ of the water and replacing it with clean water at the same salinity and temperature. Fish were fed daily ad libitum with granules (Aphymar, Mèze, Hérault, France) until two days before sampling. Fish were anesthetized using benzocaine at $50 \mathrm{ppm}$ prior to any manipulation. Fish mean fork length and body weight have been determined before sampling. Anterior and posterior intestines were sampled and subdivided into two segments, a proximal and a distal segment. For 
gene expression analysis, the distal segment of each intestinal region (anterior and posterior intestine) were collected. For protein analysis, the proximal segment of each intestinal region was collected. For histology, anterior intestines (distal segments) and posterior intestines (proximal segments) were collected.

For mRNA analysis, samples were flash frozen in liquid nitrogen and stored at $-80{ }^{\circ} \mathrm{C}$. For protein analyses, samples were stored at $-80{ }^{\circ} \mathrm{C}$ in SEI buffer $(300 \mathrm{mM}$ sucrose, $20 \mathrm{mM}$ $\mathrm{Na}_{2}$ EDTA, $100 \mathrm{mM}$ imidazole, $\mathrm{pH}$ 7.4) containing compete EL ${ }^{-}$A-free proteinase inhibitors (Roche, Mannheim, Germany). For histology, samples were im $\eta_{1 \cdots}$ ed for $48 \mathrm{~h}$ in Bouin's liquid then rinsed in $\mathrm{EtOH}$ at $70 \%$ for several weeks. The anima' experimentations followed the rules of the European Union (Instruction 86/609) and the Frenc: raw (decree 87/848).

\subsection{RNA extraction and complementary $c^{\prime} / N /$ synthesis}

Nucleospin ${ }^{\circledR}$ RNA (MACHEREY NA TEL GMbH Co.KG, Germany) extraction kit was used for total RNA extraction and DNA e r atment. The A260/A280 ratio was determined using a NanoDrop ${ }^{\circledR}$ One Spectrophotc neter (ThermoFisher, USA). RNA was only used when the A260/A280 nm ratio was $n^{h} 0 \cdot 1.9$ and A260/A230 nm ratio was above 2.0. First-strand cDNA synthesis was done with $1 \mu \mathrm{g}$ RNA using qScript ${ }^{\mathrm{TM}}$ cDNA SuperMix (Quanta Biosciences ${ }^{\mathrm{TM}}$ ) and the necessary reagents including random primers, oligo primers and qScript reverse transcriptase. cDNA samples were stored at $-20^{\circ} \mathrm{C}$.

\subsection{Quantitative real-time RT-PCR}

The primers used in this study are indicated in Table 1. $0.75 \mu \mathrm{L}$ of SensiFAST ${ }^{\mathrm{TM}}$ SYBR ${ }^{\circledR}$ NoROX Kit (Bioline, UK), $0.037 \mu \mathrm{L}$ of each primer (at $0.4 \mu \mathrm{M}$ ), $0.21 \mu \mathrm{L}$ of ultra-pure water and 
$0.5 \mu \mathrm{L}$ of diluted cDNA (diluted at 1/16) were dispensed into a 384-well reaction plate in an Echo ${ }^{\circledR} 525$ liquid handling system (Labcyte Inc., San Jose, CA, USA). Generated standard curves determined the cDNA dilution for each primer pair. One sample was run in duplicates in this program. The qRT-PCR procedures were described below: initial denaturation $\left(1\right.$ cycle, $95{ }^{\circ} \mathrm{C}$, $150 \mathrm{~s}$ ), denaturation $\left(45\right.$ cycles, $\left.95{ }^{\circ} \mathrm{C}, 15 \mathrm{~s}\right)$, hybridization $\left(1\right.$ cycle, $\left.60{ }^{\circ} \mathrm{C}, 5 \mathrm{~s}\right)$, elongation $(1$ cycle, $\left.72{ }^{\circ} \mathrm{C}, 10 \mathrm{~s}\right)$ and a final step $\left(1 \mathrm{cycle}, 40{ }^{\circ} \mathrm{C}, 30 \mathrm{~s}\right)$. The amplification specificity was controlled by a melting curve program. The no-template control $\iota$ sed ultra-pure water in this program. Efficiencies were measured and are indicated in Tarls: rithe geometric mean of three reference genes normalized the expression levels using ve $\Delta \Delta \mathrm{Ct}$ calculation with the MSW condition as a control condition. The three reference $=$ nes used were the elongation factor (efl $\alpha$ ), ribosomal protein L13 (l13) and ribos or d protein S30 fusion gene (fau). Relative quantifications were performed using the net.lod of Vandesompele et al. (2002). The threshold cycle $(\mathrm{Ct})$ of the three reference genes $\mathrm{d}_{\imath}{ }^{\prime}$ not change at the tested conditions $(P<0.05)$.

\subsection{Morphology of the intestine. nd immunofluorescence}

After extensive rinses in $7 \iota^{0}$ ethanol, intestine samples were dehydrated in a graded ethanol series and embedded in ? 'raplast (Leica). Transverse sections $(5 \mu \mathrm{m})$ were cut on a microtome (Leitz RM2235). Then the sections were collected on poly-L-lysine-coated glass slides and were stained using the Masson's Trichrome staining protocol (Junqueira et al. 1979). Slides from at least 3 animals per condition were observed and representative anterior and posterior intestine sections were photographed under a Leica Diaplan microscope. For morphometric analyses, the enterocyte perimeter and area were measured from the basal membrane of the cells up to the base 
of the apical microvilli using the Image $\mathbf{J}$ software (ImageJ $\mathrm{ij} 152$ ). In each condition, 3 animals have been compared and 8 measurements per animal have been done.

For immunofluorescence, sections were dewaxed (Histochoice), hydrated through a descending series (from $100 \%$ to $50 \%$ ) of ethanol baths and rinsed in phosphate-buffered saline (PBS), pH 7.4. Slides were then immersed in a solution containing $0.02 \%$ Tween $20,150 \mathrm{mM}$ $\mathrm{NaCl}$ in PBS, pH 7.3 for 10 min. Sides were incubated for $20 \mathrm{~min}$ in $5 \%$ bovine serum albumin (BSA) in PBS, then rinsed three times with PBS. Primary labeling v' 's performed overnight in a humid chamber placed on a shaker at $4{ }^{\circ} \mathrm{C}$. Following antibod: os ...ere used: mouse monoclonal antibody raised against chicken $\mathrm{Na}^{+} / \mathrm{K}^{+}$-ATPase $\alpha 5$ (depos. ted to DSHB, University of Iowa) at $44 \mu \mathrm{g} / \mathrm{mL}$, monoclonal mouse antibody (T4 recognizing " $\mathrm{KCC} 1 / 2$ and NCC: Iowa Hybridoma Bank, University of Iowa, IA. USA) at $10 \mu \mathrm{g} / \mathrm{m}$ ar d polyclonal antibody produced in rabbit raised against Japanese medaka (Oryzias ati es) AQP8ab (displaying the same epitope than in European sea bass) (Madsen et al. 2014) at $5 \mu \mathrm{g} / \mathrm{mL}$ in $0.5 \%$ bovine serum albumin (BSA) in PBS. Negative controls were prepard . hout the primary antibodies. After three washes in PBS to remove unbound antibody, this seccions were incubated for one hour at room temperature in a humid chamber with the saro ${ }^{2}$ ry antibodies at $10 \mu \mathrm{g} \cdot \mathrm{mL}^{-1}$ (goat anti-mouse Alexa Fluor 594, Invitrogen, Life Technoı g,es) and $4 \mu \mathrm{g} \cdot \mathrm{mL}^{-1}$ (goat anti-rabbit Alexa Fluor 488, Thermo Fisher Scientific). Following PBS washes, nuclei were counterstained with 4', 6-diamidino-2phenylindole (DAPI, Sigma) for 5 minutes. Sections were thoroughly washed in PBS and mounted in an anti-bleaching mounting medium (Immuno-histomount, Santa Cruz Biotechnology). Slides were then observed with a Leica DM6B microscope equipped with a special filter set for fluorescence and coupled to a Leica DMC 2900 digital camera. 
2.5 Protein extraction, NKA activity assay and AQP8ab immunoblotting

Fish intestines stored in SEI buffer were thawed on ice for protein analyses. Tissues were homogenized by a Retsch Mixer mill MM400 (Haan, Germany) using the frequency of $30 \mathrm{~Hz}$ for $1 \mathrm{~min}$. After centrifugation at $1500 \mathrm{~g}\left(10 \mathrm{~min}, 4{ }^{\circ} \mathrm{C}\right)$, the supernatant containing the membranes was used for protein quantification (Bradford; Bio-Rad, France) and NKA activity measurements.

NKA activity was measured using a colorimetric assay based un the generation of inorganic phosphate by the NKA with and without ouabain (Tang et al $\bumpeq n_{1} \sim, 340 \mu \mathrm{L}$ of reaction medium (final concentration: imidazole, 100 mM; NaCl, 125 mM; $ı$ Cl, 75 mM; $\mathrm{MgCl}_{2}, 7.5$ mM; pH 7.6) was mixed with $10 \mu \mathrm{L}$ of protein sample $(100 \mu \mathrm{g} / \mu \mathrm{L}), ? \mathrm{mM} \mathrm{Na}_{2} \mathrm{ATP}$, and $0.5 \mathrm{mM}$ ouabain (final concentrations) or deionized water. To tes th potential of NKA activity, the different groups were incubated at $37{ }^{\circ} \mathrm{C}$ for $20 \mathrm{mi}$. an $\lrcorner$ the reaction was terminated in a freezer $\left(-20{ }^{\circ} \mathrm{C}\right)$ for $10 \mathrm{~min}$. The colorimetric reagent (an. monium molybdate, $10 \mathrm{~g} / \mathrm{L} ; \mathrm{H}_{2} \mathrm{SO}_{4}, 0.9 \mathrm{M}$; Tween-20, $10 \mu \mathrm{L} / \mathrm{mL}$ ) was mixed in equal $\mathrm{v}^{\wedge} \mathrm{ur}$. measured at $405 \mathrm{~nm}$ in a microp' ate ıeader (TECAN trading AG, Switzerland) to calculate NKA activity. The absorbance $\sim \mathrm{f} \bullet \boldsymbol{n}$ sample was determined in triplicate and a mean value was determined.

For immunoblotting, proteins $(5 \mu \mathrm{g})$ were mixed with $0.4 \mu \mathrm{L} \beta$-mercaptoethanol (SigmaAldrich, Germany) and 3.6 $\mu \mathrm{L}$ loading buffer (Bio-Rad, Marnes la Coquette, Hauts-de-Seine, France). Then the proteins were separated by electrophoresis using sodium dodecyl sulfatepolyacrylamide gels (Bio-Rad, Marnes la Coquette, Hauts-de-Seine, France). Proteins were then transferred for $2 \mathrm{~h}$ on a PVDF membrane (WESTRAM Clear Signal, Schleicher and Schuell, VWR, Val-de-Marne, France) using a wet transfer apparatus (Bio-Rad, Marnes la Coquette, 
Hauts-de-Seine, France). After transfer, the blots were incubated for $1 \mathrm{~h}$ in a commercial blocking buffer (LI-COR Biosciences, Lincoln, NE, USA). After rinsing with PBS, the blots were incubated overnight in a humid chamber placed on a shaker at $4{ }^{\circ} \mathrm{C}$ with a polyclonal antibody produced in rabbit and raised against Japanese medaka (Oryzias latipes) AQP8ab (Madsen et al., 2014) at $5 \mu \mathrm{g} / \mathrm{ml}$ diluted in blocking buffer with Tween $20(2 \mu \mathrm{L} / \mathrm{mL})$, followed by rinsing and incubation with a secondary antibody, goat anti-rabbit IRDye ${ }^{\circledR} 800 \mathrm{CW}(0.05$ $\mu \mathrm{L} / \mathrm{mL}$, LI-COR Biosciences, Lincoln, NE, USA) diluted in blocking buffer with Tween 20 (2 $\mu \mathrm{L} / \mathrm{mL}$ ) and $10 \%$ SDS. Following washes, immunorea tive vands were visualized and photographed using the Odyssey® Fc Imaging System TI-COR Biosciences, Lincoln, NE, USA). The results were converted to numerical values , compare protein abundances of the immunoreactive bands (relative to twice the $\sin ^{-1}$ e samples used as a reference) using the software Image J (ImageJ ij152).

\subsection{Statistical analyses}

Statistical analyses were peı. ㄱrmed using GraphPad Prism (version 8, GraphPad Software Incorporated, La Jolla, CA $\supset_{0}$ ? JSA). Normality and homogeneity tests were verified using the D'Agostino-Pearson anc Bartlett tests. If the data fit with these conditions, a two-way ANOVA analysis was performed with salinity and the lineages as main factors followed by a Tukey's multiple comparisons test. For NKA activity, a three-way ANOVA analysis of variance with salinity, the lineages and the tissue (anterior or posterior intestine) as main factors was performed followed by a Tukey's multiple comparisons test. Conversely, if normality and homogeneity of variances were not verified, Kruskal-Wallis test was performed followed by a Dunn's multiple comparisons test. Data are represented as box and whisker plots (from the first quartile to the 
third quartile) showing median, minimum and maximum values. Morphometrical data are represented using the mean $+/-$ SD. Statistical differences were accepted at $P<0.05$. Principal component analysis (PCAs) was performed using standardized individual gene expression values and NKA activities using Rstudio (version 1.2.5001) and the factoextra, missMDA and FactoMineR packages (Lê et al., 2008).

\section{Results}

D. labrax analyzed in this and a previous study were chncented by a similar length and slight differences in weight $(18.30 \pm 6.49 \mathrm{~g} \sim 27.65 \pm 13.51 \mathrm{~g}$, 'Cao et al., 2021). Mortality was low with one death observed both in the MSW and MHW gro. , after 1 and 4 days of transfer.

\subsection{Morphometric analysis in the intestine}

Anterior and posterior intestinal sect $、 n s$ were observed in 3 fish per condition focusing on enterocytes that are characterized h: al s pical brush border facing the intestinal lumen (Fig. 1AD). The hematoxylin staining o the nuclei was much more visible in intestinal sections of fish maintained in hypersaline tha. in seawater conditions whatever the intestinal section observed (for posterior intestine, s` Fig. 1A-D). The size of intestinal enterocytes has been measured in each condition using the cell perimeter and the cell area (Table 2, Fig. 1E, F). The data showed a significantly higher value for the cell perimeter (25-50\% higher) and area (180-252 \% higher) in HW groups compared SW groups, with a clear effect of salinity $(P<0.0001)$ for both measured parameters and both tissues. There was also a lineage effect $(\mathrm{p}<0.001)$, except for the cell area in the anterior intestine, with a tendency of having slightly lower values in Atlantic than Mediterranean D. labrax. (Table S1). 
3.2 NKA activity and $n k a, n k c c 2$ mRNA expression in the intestine

Overall, higher NKA activities were observed in hypersaline conditions compared to seawater $(P<0.0001)$. More specifically, in the posterior intestine (Fig. 2A, blue), NKA activities were higher in HW than SW whatever the population. In the anterior intestine however (Fig. 2A, red), a different trend was observed for NKA activity with a significantly higher value in MSW than in the other conditions. No differences were observed between sam.ities in the Atlantic lineage for this tissue. Overall, there was a clear effect of th $1_{1 \ldots}$ age with higher values in Mediterranean than in Atlantic populations $(P<0.0001)$, hatever the tissue considered. When comparing anterior and posterior intestine, differences 1 . $\mathrm{NKA}$ activity were observed only in hypersaline conditions with significantly higher ${ }^{\top} \mathrm{K} f$. activities in the posterior intestine $(P<$ 0.0001). Overall, a significant effect of the tis de was detected $(P<0.0001)$ (Table S2).

In the posterior intestine, $n k a$ ala exp ession was higher in hypersaline conditions $(P<0.01)$ with a significant difference betwren c'linities in the Atlantic lineage. A significant lineage effect was also observed with 'owtr $n k a$ ala expression levels in SW for the Atlantic fish compared to Mediterranean $\mathrm{f}_{1 \mathrm{~s}}$ ',$P<0.01$ ) (Table S1, Fig. 2B). $n k c c 2$ was significantly higher in HW compared to SW w hatever lineages $(P<0.0001)$ (Fig. 2C). Nka $\alpha 1 a$ and $n k c c 2$ mRNA expressions from anterior intestine were not shown, as there was no difference among different groups.

3.3 AQP8ab protein level and aqp8 mRNA expression in the posterior intestine

Immunoblots showed one single band for AQP8ab at about $27 \mathrm{kDa}$ in each condition (Fig. 3A). Relative AQP8ab protein levels were quantified, and the hypersaline-acclimated individuals 
showed significantly higher AQP8ab protein levels than the SW-acclimated individuals in both lineages (salinity effect: $P<0.0001$, Table S1). Among the different AQPs, aqp8ab was the most expressed paralog in MSW (Fig. S2). Comparing experimental conditions, there was a significant salinity effect for $a q p 8 a b$ and $a q p 8 a a(P<0.0001)$ (Table S1; Fig. 3B, C). Aqp 8ab mRNA levels were slightly but not statistically higher in AHW compared to ASW but significantly higher in MHW compared to MSW (Fig. 3B). Aqp 8aa mRNA levels were slightly but not statistically higher in MHW compared to MSW but i $\mathrm{g}_{\mathrm{L}}$ : ficantly higher in AHW compared to ASW (Fig. 3C). However, for $a q p 8 b$, the tf ndt $1 c y$ was reversed with a lower expression in hypersaline media compared to seawater t+..t v. as significant in Mediterranean sea bass (Fig. 3D). MSW showed significantly higher aqr $8 b$ : vels than all the other conditions. A significant lineage effect (Table S1; $P<0.001$ ) wa w ubserved for AQP8ab protein and $a q p 8 a b$, aqp $8 b$ transcript levels in Mediterranean . a bass compared to Atlantic sea bass with higher levels in Mediterranean sea bass.

\section{4 mRNA expression of othe $7 q$. .porins in the intestine}

In the posterior intes $\mathrm{Int}$ a significant higher aqp $1 a$ expression was observed in $\mathrm{SW}$ compared to HW groups (Fig. 4A) $(P<0.0001)$. Marked differences in aqp la expression between lineages were observed in SW with higher expression levels in MSW than in ASW. This was also the case for $a q p 1 b$, however for this paralog, no difference in expression was observed between salinities for Atlantic fish (Fig. 4B). Overall a significant salinity $(P<0.0001)$ and lineage $(P<0.001)$ as well as an interaction $(P<0.0001)$ between these two factors were observed for aqp $1 a$ and $a q p 1 b$ (Table S1). For aqp 10b, no salinity effect was observed. 
However, a significant higher expression was observed in the Mediterranean lineage than the Atlantic lineage (lineage effect: $P<0.001$ ) (Table S1; Fig. 4C).

In the anterior intestine, there was no difference in expression between different conditions for aqp 1a, aqp 1b, aqp $8 a a, a q p 8 b$ and $a q p 10 b$ (results not shown). For $a q p 8 a b$ however, mRNA levels were higher in hypersaline water compared to seawater in the Atlantic lineage (Fig. S1). There was an effect of salinity (Table S1; $P<0.01$ ) but no lineage effect for $a q p 8 a b$.

\subsection{Principal component analysis}

Principal component analysis (PCA) results were obta. ned from the posterior intestine for

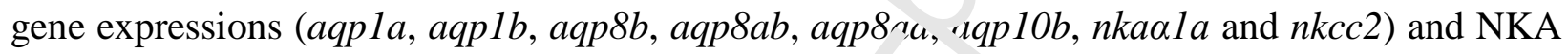
activity (Fig. 5). Principal component 1 (PC1) 'as ribed 36.8\% of the original information whereas PC2 described $27.3 \%$, making a of the contributors to the principal comp nent, the variables in PC1 and PC2 were compared (Fig. 5A). Aqp8aa, aqp8ab and $n k c c 2$ g u up ar, together with positive loading on the right upper side

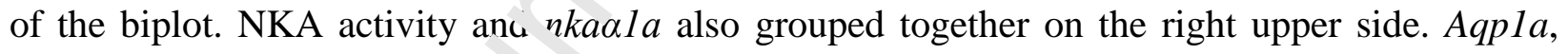
$a q p 1 b, a q p 8 b$ and $a q p 10^{r}{ }^{a} \mathrm{D}_{\mathrm{r}}$ ared with negative loading on the left side of the biplot. PCA individual factor maps $w$ re shown in Fig. 5B with the same variables. D.labrax maintained in SW appeared on the left side of the biplot with a clear population structuration along the PC2 axis. In HW, sea bass appeared on the right side of the biplot with no clear structuration along the PC2, however, AHW individuals more closely clustered together than MHW, that were more dispersed. 
3.6 In situ immunofluorescence of $\mathrm{NKA \alpha}, \mathrm{AQP} 8 \mathrm{ab}$ and $\mathrm{NKCC} / \mathrm{NCC}$ in anterior and posterior intestine

$\mathrm{NKA} \alpha, \mathrm{AQP} 8 \mathrm{ab}$ and NKCC/NCC were immunolabeled using intestinal sections from at least 3 animals per condition. Control sections without primary antibody showed no immunolabeling (results not shown). No apparent difference was observed in NKAa, NKCC/NCC and AQP8b staining between the four conditions, therefore representative images of one condition were shown. NKA basolateral staining was strong in enterocytes of all u erved images (Fig. 6A, 7D) as widely known.

In the anterior intestine, AQP8ab was localized in th subapical area of enterocytes just underneath the brush border (Fig. 6A-D, green stain. y). In a few single cells, a strong basolateral staining was recorded (Fig. 6A-B, $\left.\mathrm{a}_{1} \mathrm{~s} \mathrm{w}_{3}\right)$. NKCC/NCC using the polyclonal T4 antibody stained the brush border men. ra'es apically (Fig. 6C, fuchsia staining) with no subcellular colocalization with AQP8ab ( iig. 6C).

The posterior intestine was chara rized by different enterocyte types regarding their structure and membrane proteiı expression and localization. Deep invaginations were observed (Fig. 7A-C) with very faint a.d diffuse AQP8ab staining, sometimes stronger in the subapical parts (Fig. 7C). NKCC, NCC apical staining was observed only in the proximal part of the invaginations (Fig. 7B, arrow), and no staining in the distal part of the invaginations (Fig. 7A). Shorter invaginations were observed in more distal parts of the intestine, probably the rectum with the presence of numerous mucocytes (Fig. 7D-F). The AQP8ab subapical staining was more diffuse but stronger and withdrawn to the cytosolic compartment (Fig. 7E, F). Only a faint apical NKCC/NCC staining was observed in this section (Fig. 7E). 


\section{Discussion}

Extreme events due to climate change have become more frequent in the last decade of the 21th century (Donat et al., 2016). The Mediterranean region frequently experienced extreme climate events like unusual high temperatures and the magnitude and frequency of these events are expected to increase in the future (Kim et al., 2019). In the Mediterranean Sea, the salt content is steadily increasing due to decreasing precipitations (Krahmann and Schott 1998), increasing evaporation (Mariotti 2010) and reduction in freshwater :nflow (Rohling and Bryden

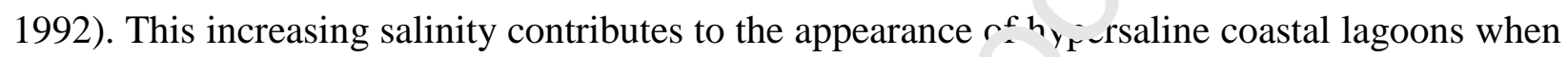
connectivity with the sea is limited and freshwater inpu. is lower than the evaporation rate. European sea bass enter these habitats in spring and dur ${ }_{1 .}$ the summer season and are extremely tolerant to salinity changes and known to tolerat' h' persaline environments (Varsamos et al., 2002; Cao et al., 2021) as well as fresh wa or 'Lorin-Nebel et al., 2006; L'Honoré et al., 2019).

4.1 Intraspecific differences in the $\cdots \mathrm{pr}$, ion patterns of key ion transporters and water channels

Increasing literature is avaiin hle on intraspecific variability showing that wild populations experiencing contrasted enrsur.mental conditions can undergo phenotypic changes leading to differential physiologicai nerformance and organism tolerance (Stitt et al. 2014; Metcalfe et al. 2016; Sunde et al. 2018; Christensen et al. 2019; Donelson et al. 2019; McKenzie et al. 2020). Intraspecific variation in expression patterns in relation to salinity and thermal tolerance were measured in two populations of killifish (Fundulus heteroclitus) from the northern and southern extremes of the species range along the Atlantic coast of North America from temperature and salinity contrasting environments (Scott et al., 2004; Fangue et al., 2006). A higher seawater tolerance and differential gene expression patterns were measured in North Sea European 
flounder (Platichthys flesus) compared to Baltic Sea flounders that experience lower salinities in their natural habitats (Larsen et al., 2008). Intraspecific differences in the effect of salinity were also observed in European perch (Perca fluviatilis) regarding swimming performance and metabolism (Christensen et al., 2019). In European sea bass, intraspecific differences in salinity tolerance have previously been investigated within the West Mediterranean lineage for fresh water (Lorin-Nebel et al., 2006; Giffard-Mena et al., 2008; Guinand et al., 2017; L'Honoré et al., 2019, 2020) and more recently between Atlantic and Mediterranen n sea bass for hypersalinity (Cao et al., 2021). PCA analysis on individuals showed a clear $d_{1}$ ín. ence between Mediterranean and Atlantic sea bass using physiological parameters analy ${ }_{\llcorner}{ }^{\circ} \mathrm{d}$ in this study in posterior intestines which shows a different handling of solute-coupled wate cansport in this organ. We observed a striking difference in posterior intestine $\mathrm{NKA}^{\mathrm{A}} \mathrm{dc}^{1}$, vity and $n k a$ ala expression between Mediterranean and Atlantic D. labrax wi. $\urcorner s^{i}$ gnificantly higher levels in the Mediterranean sea bass, notably in the seawater condition (a"ound 2.5 times higher NKA activity in MSW vs ASW). Interestingly, we also found a sim:lar trend for NKA activity at the kidney level (Cao et al., 2021). This raises the question on the underlying metabolic costs and if they differ between genetic lineages, as NKA $\approx$ a $h$ :ghly energy consuming pump. Regarding aquaporin expression levels, Mediterranean sia bass had significantly higher aqp1a, aqp8b, aqp1b and aqp10b expression than Atlantic sea bass in SW which might be linked to an overall higher water transport in SW conditions in the saltier Mediterranean Sea at around 38 \%o (Yilmaz et al., 2020), than in the Atlantic Ocean, at around $36 \%$ (Qu et al., 2013). Mediterranean D. labrax seem therefore to more actively reabsorb ions at the kidney and intestinal level than Atlantic sea bass in order to efficiently take up water and to maintain constant blood osmolalities (Cao et al., 2021). A stronger expression of $a q p l a$ and $a q p l b$ was observed in Mediterranean sea bass in SW 
in comparison to Atlantic sea bass which could be linked to their different habitats. GiffardMena et al. (2007) have shown that posterior intestine and rectum of Mediterranean sea bass highly express AQP1 in SW compared to fresh water (FW), which indicates an inverted Ushaped relationship to salinity with strong expression in SW and low expression in FW and HSW. Studies in the silver sea bream Sparus sabra have shown that cortisol administration increased aqpla expression in SW (33\%) (Deane et al., 2011) and we also know from previous studies that cortisol triggers fluid reuptake rate in fish across the posterior t. $^{+}$estine (Cornell et al., 1994). Blood basal cortisol levels of Mediterranean sea bass are $h_{0}^{i-h}-4$ the stress response is very intense compared to other teleost species which could cu ntribute to trigger water reuptake in these fish (Fanouraki et al., 2011). Cortisol levels als differ among individuals with some showing a consistent low or high response to s. ‘ss (Samaras et al., 2016). Comparisons of cortisol levels between Atlantic and Medic rr? iean sea bass could be very informative in order to better understand physiological stress re nonses and their link to the data obtained in our study. The exact role of each aquaporin p al ' $\mathrm{g}$ is not yet clear in D. labrax, but besides transepithelial water uptake, aquaporins invest $t_{c}$ ateu in this study could also be involved in intracellular volume regulation (Chauvigné et a1 2011; Sundell and Sundh., 2012) and acid-base regulation (Horng et al., 2015) which could ontribute to explain their differential expression between sea bass lineages. The differences observed in gene expression patterns and NKA activity point to a different handling of ion transport and water homeostasis between genetic sea bass lineages and intraspecific variability in physiological responses need to be further investigated in future studies.

4.2 Enterocyte size is influenced by hypersalinity 
A variety of factors including phylogeny (Davis et al., 2013), diet (Buddington et al., 1997), health (Banerjee and Ray 2017), chemicals (Yuan et al., 2010), developmental stage (GiffardMena et al., 2006) and physico-chemical parameters such as temperature (Savić et al., 2012) and salinity can considerably influence the diversity in the morphology and structure of teleost intestine. Salinity influences numerous physiological traits linked to digestive physiology such as nitrogen excretion and metabolic processes (Gracia-López et al., 2006). In common snook Centroponus undecimalis challenged to different salinities, Gracia 'ópez et al. (2006) showed changes in the absorption of energetic substances by analyzin n.i. atios.

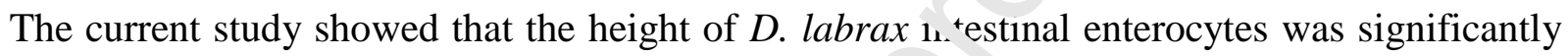
higher in the hypersaline conditions compared to sea ater levels. This could be linked to increasing membrane surface area and increased - yn hesis of transport proteins (as shown for NKA) in order to cope with dehydration. ct $^{\text {t }}$ ange in enterocyte size has previously been shown in this species under starvation followe ${ }^{-1}$ by postfeeding (Alix et al., 2017) indicating a high plasticity of intestinal cells to envir $\sim n$. r.tal factors. All fish were fed in our study until two days prior to sampling so the chang in structure of enterocytes at $55 \%$ compared to $36 \%$ is not linked to food deprivation ' $\mathcal{H}^{-1}$,ert and Doroshov 2003; Rios et al., 2004; Ostaszewska et al., 2005). In our research, $w$ also observed more visible nuclei in the enterocytes in the hypersaline conditions which could also be linked to increased protein synthesis by enterocytes in the hypersaline environment. Elevated salinity may change nutrient digestion capacity through the induced morphological changes in the intestine. Nutrient digestibility in most fish species have been studied in relation to nutritional/dietary factors (Köprücü and Özdemir 2005; Tram et al., 2011; Zhou and Yue 2012). Tran-Ngoc et al. (2017) showed that salinity changes can modify intestinal morphology and digestibility of nutrients, notably in the distal region. We have 
observed morphological differences in both regions of the intestine, but other parameters than cell height could be investigated in the future such as goblet cell density, length of the intestine and abundance of intestinal folds. It cannot be excluded that the increase in enterocyte size also affects protein, lipid and carbohydrate uptake mechanisms, as nutrient uptake by different transporters is tightly linked to electrochemical gradients generated by the NKA.

\subsection{Intestinal ion transport upon high salinity transfer}

NKA is known to be the primary driving force for water $+\cdots \eta_{\bar{S}_{\tilde{F}}}$ ort through the generation of ionic and osmotic gradients between the lumen and the blou f(Larsen and Møbjerg 2006) leading to ion absorption via ion channels, co-transporters and in , ardly directed water flow (Sundell and Sundh 2012). In HW, a higher NKA activity wa ('pe sted to optimize water uptake mechanisms (Laverty and Skadhauge 2012). PCA anal sis showed a strong correlation between NKA activity and $n k a \alpha l a$ expression in the posterior $\div$ testine, probably linked to the increase in NKA activity and $n k a$ ala expression at high s? ${ }^{1:}$ ni., In anterior intestine, no increase was observed which clearly shows different responst. between intestinal sections to hypersalinity. A response to high salinity at the posterior in ${ }^{+\infty} \mathrm{sti}^{\sim} \boldsymbol{c}$ level has been observed also in Plotosus lineatus, with higher NKA activity levels at $50 \%$ compared to $34 \%$ following 14 days acclimation, and no difference in the anterior intestine (Malakpour et al., 2018).

Studies in marine fish have shown that NKA is not the only pump involved in intestinal ion uptake in hypersaline water, V-type $\mathrm{H}^{+}$ATPase (VHA) seems also be highly expressed and apically located in enterocytes (Grosell et al., 2010; Guffey et al., 2011). Guffey et al. (2011) have shown in gulf toadfish (Opsanus beta) that VHA was strongly expressed in the posterior intestine at $60 \%$, as a response to high luminal $\mathrm{HCO}_{3}{ }^{-}$levels generated by enhanced $\mathrm{HCO}_{3}{ }^{-} / \mathrm{Cl}^{-}$ 
exchange (Guffey et al., 2011). Also, in this latter study, NKA activity showed differential responses only in anterior intestine which differs from our study in D. labrax. It would be worth analyzing VHA as well as $\mathrm{HCO}_{3}{ }^{-} / \mathrm{Cl}^{-}$exchanger in D. labrax to compare their expression in both intestinal sections.

In the posterior intestine of California Mozambique tilapia, NKA activity was higher in $60 \%$ acclimated fish relative to those acclimated to $30 \%$ for 14 days (Sardella et al., 2008) as shown in D. labrax.

High activity of the NKA in hypersaline conditions mav $d_{r_{1}:=}$ to increased ion absorption through $\mathrm{Na}^{+}-\mathrm{Cl}^{-}$cotransport, $\mathrm{Na}^{+}-\mathrm{K}^{+}-2 \mathrm{Cl}^{-}$cotransporters al ${ }^{-} \mathrm{Cl} / \mathrm{HCO}_{3}{ }^{-}$exchanger (Grosell 2006; Ronkin et al., 2015). Nkcc2 was significantly higher 1 . HW compared to SW whatever the considered lineage in the posterior intestine, ard rot in the anterior intestine. Considering that NCC/NKCC is apically localized in ente ' ${ }^{\prime} \mathrm{CV}^{\prime} \mathrm{es}$ (Lorin-Nebel et al., 2006) as previously shown in Japanese eel (Watanabe et al., 2011) and Mozambique tilapia (Li et al., 2014), this is consistent with our hypothesis on the i, volvement of the posterior intestine in ion uptake in hypersaline medium and not the anterior intestine. Japanese eels acclimated to seawater showed higher $n k c c 2 b$ mRNA exrmes: $r n$ in both anterior and posterior intestine when compared with freshwater acclimated et:- (Watanabe et al., 2011), but hypersalinity was not investigated in this species. A significant up-regulation of $n k c c 2$ was also observed in Mozambique tilapia in the posterior intestine at $70 \%$ compared to seawater (30\%) (Li et al., 2014). Different results were found in the Gulf toadfish and the sea bream, where an increased expression of the $n k c c 2$ was found in the anterior intestine during hypersalinity exposure (Grosell 2011; Gregorio et al., 2013).

4.4 Intestinal water reabsorption upon high salinity transfer 
Aqpla and aqp8 are considered as true water pores, and aqp10 presumably has additional permeability to glycerol (Cerdá and Finn 2010). Contrary to other species where intestinal $a q p 10 b$ expression was low in the middle intestine when environmental salinity increased as European silver eels (Martinez et al., 2005), Atlantic salmon (Tipsmark et al., 2010) and Japanese eels (Kim et al., 2010), no change in the expression of this paralog has been measured in D. labrax.

AQP8ab is the main AQP8 paralog participating in water reabsu.ntion across the intestine of the SW-acclimated salmon (Madsen et al., 2015) and this is according to gene expression levels (Fig. S2). Our dà supported a physiological role of AQP8ab in the transcellular water reuptake across in , cinal enterocytes upon hypersalinity exposure. Relative AQP8ab protein levels were $\mathrm{n}$ act higher in $\mathrm{HW}$ than in $\mathrm{SW}$ for both European sea bass lineages which was $\mathrm{cc}$ ? sic ent with the increased transcript levels of $a q p 8 a b$ during acclimation from SW to HW, even if not significant for the Atlantic D. labrax. Aqp1 and $a q p 8 a b$ expressions have been sh $\sim w_{1}$ to be higher in intestine when environmental salinity increased in Atlantic salmon ( $\mathrm{T}_{\mathbf{i}}{ }^{\prime}$ 'smark et al., 2010; Engelund et al., 2013), Japanese eel (Kim et al., 2010) and sockeye salmol. "'thoi et al., 2013), which is linked to the increased drinking rate and assumes an increast.' water transport capacity. In European sea bass however, aqp la and aqp $1 b$ (the latter only for Mediterranean sea bass) were less expressed in posterior intestine in HW-acclimated fish compared to SW as previously shown at kidney level (Cao et al., 2021) indicating that AQP1a and AQP1b, contrary to AQP8ab, are not increasing water uptake capacity in this species following hypersalinity transfer neither in the intestine nor in the kidney. Similarly, aqp la mRNA levels were reported to be lower when environmental salinity increased in the intestine of black porgy (An et al., 2008) and Japanese medaka (Madsen et al., 2014). 
AQP8ab subcellular immunostaining was not identical in different sections of the intestine suggesting a different involvement of enterocyte types in water and ion transport. AQP8ab was localized in the subapical area of enterocytes underneath the brush border stained by NKCC/NCC in the anterior intestine, which clearly supports the hypothesis of a functional link between AQP8ab and NKCC/NCC in those enterocytes and a solute-linked water reuptake. In the posterior intestine, a more diffuse staining was observed, but no colocalization with NKA, which could be interpreted as a vesicular staining. In mammals, $A C^{\mathbf{D}} 8$ is in fact considered as a vesicular water channel that can redistribute to plasma memª ${ }^{2}-r_{1}=$ upon need (Gradilone et al., 2003). A similar mechanism could be suggested in D. m. hrax posterior intestine with a high AQP8ab expression in intracellular vesicles and an ins c con into the apical membrane when water uptake mechanisms are activated. Inte"e $n$, ly, in the posterior intestine, subapical AQP8ab immunostaining was also obser ad in some enterocytes expressing NKCC2/NCC. We have not immunolocalized other AQP pa-alogs, however the possibility of other AQP paralogs in

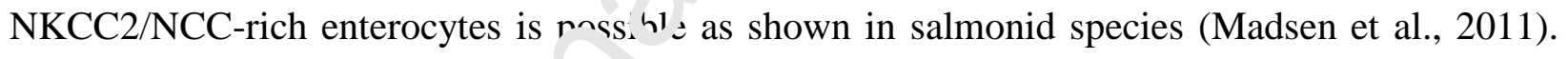
Also, water transport through naracellular pathways (Madsen et al., 2014) has not been investigated in our study $n$ nd $r$. ould be investigated to have a full comprehension of intestinal water transport in hypers. 'ine environments.

\section{Conclusion}

This study shows that European sea bass possess powerful mechanisms at the posterior intestinal level to cope with hypersalinity, contributing to their euryhalinity. Morphological changes of the intestinal epithelium (size of enterocytes) suggest more active cells in hypersaline compared to seawater. At the molecular level, responses to hypersalinity were observed with 
overall higher ion transporter expression (NKA, NKCC2) and higher water transport capacity (AQP8ab and 8aa) enabling increased solute-coupled water transport. These physiological traits were close in PCA analysis compared to the other parameters analyzed that show an opposite expression pattern ( $a q p 1 a, a q p 1 b$ and $a q p 8 b$ ) or no response to hypersalinity (aqp10). Subcellular localization of AQP8ab and NKCC2/NCC is consistent with the suggested role of these proteins in solute-coupled water transport. Our results demonstrated intra-specific differences in the expression of important osmoregulatory pro ‘ins most likely reflecting adaptive differences in ion-driven water uptake merhans within European sea bass (Dicentrarchus labrax) Mediterranean and Atla ${ }_{\text {. }}$ ic lineages. Having a different evolutionary history, these genetic lineages could furthe iverge in their physiological capacity due to the constantly increasing salinities in the "/e iterranean area in the context of climate change.

\section{Acknowledgements}

The authors would like to thank Dr. François Allal and the Ifremer team at Palavas-les-Flots for providing European sea bor $\mathrm{i}^{n}$ ages from Atlantic and West Mediterranean origin. The authors also thank Christian Tips nark for kindly giving us some AQP8ab antibody, Ivone Giffard-Mena for her valuable help in the dissection of sea bass intestines, Sophie Hermet for her precious advice in histology as well as the qPCR CeMEB (Centre Méditerranée en Environnement et Biodiversité) platform. This work has benefited from facilities funded by the 2015-2020 CPER CELIMER (French Ministry of Higher Education, Research and Innovation, Occitanie Region, Montpellier Mediterranée Metropolis, Sète Agglopole Méditerranée, Ifremer, IRD). 


\section{References}

Alix, M., Blondeau-Bidet, E., Grousset, E., Shiranghi, A., Vergnet, A., Guinand, B., Lignot, J. H., 2017. Effects of fasting and re-alimentation on gill and intestinal morphology and indicators of osmoregulatory capacity in genetically selected sea bass (Dicentrarchus labrax) populations with contrasting tolerance to fasting. Aquaculture 468, 314-325.

Allegrucci, G., Fortunato, C., Sbordoni, V., 1997. Genetic structure and allozyme variation of sea bass (Dicentrarchus labrax and D. punctatus) in the Mediterranean Sea. Mar. Biol. 128, 347-58.

An, K.W., Kim, N. N., Choi, C.Y., 2008. Cloning and expression of aquaporin 1 and arginine vasotocin receptor mRNA from the black porgy, Acanthopagrus schlegeli: effect of freshwater acclimation. Fish Physiol. Biochem. 34, 185-194.

Bagherie-Lachidan, M., Wright, S.I., Kelly, S.P., 2008. Claudin-3 tight junction proteins in Tetraodon nigroviridis: cloning, tissue-specific expression, and a ro? $\div$ in hydromineral balance. Am. J. Physiol. Regul. Integr. 294(5), R1638-1647.

Banerjee, G., Ray, A.K., 2017. Bacterial symbiosis in the fish gu and its role in health and metabolism. Symbiosis 72(1), 1-11.

Borghini, M., Bryden, H., Schroeder, K., Sparnocchia, S., Vet ano. A., 2014. The Mediterranean is becoming saltier. Ocean Sci. 10(4), 693-700.

Buddington, R.K., Krogdahl, A., Bakke-McKellep, A.M. 199, The intestines of carnivorous fish: structure and functions and the relations with diet. Acta Phys. 1l. ‘ cand. 638, 67-80.

Caccone, A., Allegrucci, G., Fortunato, C., Sbordoni, y, 197. Genetic differentiation within the European sea bass (D. labrax) as revealed by RAPD-P -R assays. J. Hered. 88, 316-324.

Cao, Q., Giffard-Mena, I., Blondeau-Bidet, E., Her ne., s., Hu, Y.C., Lee, T.H., Lorin-Nebel, C., 2021. Mechanisms of acclimation to hypersalinity ir. w o s'ropean sea bass lineages: a focus on the kidney function. Aquaculture 534, 736305.

Carvalho, E.S., Gregório, S.F., Power, D.M., C. nário, A.V., Fuentes, J., 2012. Water absorption and bicarbonate secretion in the intestine of $l_{1}$. sea bream are regulated by transmembrane and soluble adenylyl cyclase stimulation. J. Comp. $\mathrm{P}^{\mathrm{r}}$ y: $\mathrm{x}$. 3 182(8), 1069-1080.

Cerdá, J., Finn, R.N., 2010. Piscine aqıapc cirs: an overview of recent advances. J. Exp. Zool. 313A, 623650.

Chauvigné, F., Zapater, C., Cerdà J., 2011. Role of aquaporins during teleost gametogenesis and early embryogenesis. Front. Physiol. 2, 66.

Choi, Y.J., Shin, H.S., Kim, N. N., I ho, S.H., Yamamoto, Y., Ueda, H., Choi, C.Y., 2013. Expression of aquaporin-3 and- 8 mRNA' in 'he parr and smolt stages of sockeye salmon, Oncorhynchus nerka: Effects of cortisol treatment anu 'ea vat r acclimation. Comp. Biochem. Physiol. A 165(2), 228-236.

Christensen, E.A., Stieglitz, '.D., Grosell, M., Steffensen, J.F., 2019. Intra-specific difference in the effect of salinity on physiolos al performance in european perch (Perca fluviatilis) and its ecological importance for fish in estuaries. Biology 8(4), 89.

Cornell, S.C., Portesi, D.M., Veillette, P.A., Sundell, K., Specker, J.L., 1994. Cortisol stimulates intestine fluid uptake in Atlantic salmon (Salmo salar) in the post-smolt stage. Fish Physiol. Biochem. 13, 183190.

Davis, A.M., Unmack, P.J., Pusey, B.J., Pearson, R.G., Morgan, D.L., 2013. Ontogenetic development of intestinal length and relationships to diet in an Australasian fish family (Terapontidae). BMC Evol. Biol. 13(1), 1-16.

Deane, E.E., Luk, J.C., Woo, N.Y., 2011. Aquaporin 1a expression in gill, intestine, and kidney of the euryhaline silver sea bream. Front. Physiol. 2, 39.

Donat, M.G., Lowry, A.L., Alexander, L.V., O’Gorman, P.A., Maher, N., 2016. More extreme precipitation in the world's dry and wet regions. Nat. Clim. Chang. 6, 508-513.

Donelson, J. M., Sunday, J. M., Figueira, W. F., Gaitán-Espitia, J. D., Hobday, A. J., Johnson, C. R., Munday, P. L., 2019. Understanding interactions between plasticity, adaptation and range shifts in response to marine environmental change. Philos. Trans. R. Soc. B 374(1768), 20180186. 
Dufour, V., Cantou, M., Lecomte, F., 2009. Identification of sea bass (Dicentrarchus labrax) nursery areas in the north-western Mediterranean Sea. J. Mar. Biolog. Assoc. U.K. 89(7), 1367.

Duranton, M., Allal, F., Fraïsse, C., Bierne, N., Bonhomme, F., Gagnaire, P.A., 2018. The origin and remolding of genomic islands of differentiation in the European sea bass. Nat. Commun. 9(1), 1-11.

Engelund, M.B., Chauvigné, F., Christensen, B.M., Finn, R.N., Cerdà, J., Madsen, S.S., 2013. Differential expression and novel permeability properties of three aquaporin 8 paralogs from seawater-challenged Atlantic salmon smolts. J. Exp. Biol. 216(Pt 20), 3873-3885.

Fangue, N.A., Hofmeister, M., Schulte, P.M., 2006. Intraspecific variation in thermal tolerance and heat shock protein gene expression in common killifish, Fundulus heteroclitus. J. Exp. Biol. 209, 2859-2872.

Fanouraki, E., Mylonas, C.C., Papandroulakis, N., Pavlidis, M., 2011. Species specificity in the magnitude and duration of the acute stress response in Mediterranean marine fish in culture. Gen. Comp. Endocrinol. 173, 313-322.

Genz, J., McDonald, M.D., Grosell, M., 2011. Concentration of $\mathrm{M}_{3} \mathrm{SO}_{4}$ in the intestinal lumen of Opsanus beta limits osmoregulation in response to : cute hypersalinity stress. Am. J. Physiol. Regul. Integr. 300(4), R895-909.

Gracia-Lopez, V., Rosas-Vazquez, C., Brito-Perez, R., 2006. Ef. cts of salinity on physiological conditions in juvenile common snook Centropomus undecimali . Co np. Biochem. Physiol. A 145(3), 340-345.

Gradilone, S.A., Garcia, F., Huebert, R.C., Tietz, P.S., Laror: N C., Kierbel,A., Marinelli, R.A., 2003. Glucagon induces the plasma membrane insertion of functic al a juaporin-8 water channels in isolated rat hepatocytes. Hepatology 37(6), 1435-1441.

Gregório, S.F., Carvalho, E.S., Encarnação, S., Wilsc ı, ,.M., Power, D.M., Canário, A.V., Fuentes, J., 2013. Adaptation to different salinities exposes func ic al ,pecialization in the intestine of the sea bream (Sparus aurata L.). J. Exp. Biol. 216(Pt 3), 470 . .79.

Grosell, M., 2006. Intestinal anion exchange in narine fish osmoregulation. J. Exp. Biol. 209(Pt 15), 2813-2827.

Grosell, M., 2010. The role of the gastroin stinal tract in salt and water balance. In: Grosell M, Farrell AP, Brauner CJ, editors. Fish Physiolor,y The Multifunctional Gut of Fish, Vol. 30. San Diego, CA: Elsevier Inc.; 2010. pp. 135-164.

Grosell, M., 2011. Intestinal anion ex hange in marine teleosts is involved in osmoregulation and contributes to the oceanic inorganic ca, 'on cycle. Acta Physiol. 202(3), 421-434.

Grosell, M., Mager, E.M., Wil'ian- C., Taylor, J.R., 2009. High rates of $\mathrm{HCO}_{3}^{-}$secretion and $\mathrm{Cl}^{-}$ absorption against adverse gre dien in the marine teleost intestine: the involvement of an electrogenic

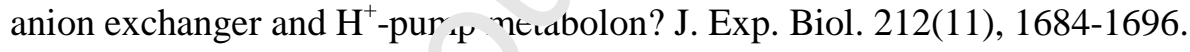

Giffard-Mena, I., Boul V A joulat, F., Fowden, H., Castille, R., Charmantier, G., Cramb, G., 2007. Aquaporin molecular char terization in the sea-bass (Dicentrarchus labrax): the effect of salinity on AQP1 and AQP3 expressi $\sim r$. Comp. Biochem. Physiol. A 148(2), 430-444.

Giffard-Mena, I., Charmantier, G., Castille, R., 2007. The role of the gut in salinity adaptation of the seabass Dicentrarchus labrax during larval development. Comp. Biochem. Physiol. A 4(146), S94.

Giffard-Mena, I., Charmantier, G., Grousset, E., Aujoulat, F., Castille, R., 2006. Digestive tract ontogeny of Dicentrarchus labrax: Implication in osmoregulation. Dev. Growth. Differ. 48:139-151.

Giffard-Mena, I., Lorin-Nebel, C., Charmantier, G., Castille, R., Boulo, V., 2008. Adaptation of the seabass (Dicentrarchus labrax) to fresh water: role of aquaporins and $\mathrm{Na}^{+} / \mathrm{K}^{+}$-ATPases. Comp. Biochem. Physiol. A 150(3), 332-338.

Gisbert, E., Doroshov, S.I., 2003. Histology of the developing digestive system and the effect of food deprivation in larval green sturgeon (Acipenser medirostris). Aquat. Living Resour. 16, 77-89.

Gonzalez, R.J., 2012. The physiology of hyper-salinity tolerance in teleost fish: a review. J. Comp. Physiol. B 182(3), 321-329.

Guinand, B., Vandeputte, M., Dupont- Nivet, M., Vergnet, A., Haffray, P., Chavanne, H., Chatain, B., 2017. Metapopulation patterns of additive and nonadditive genetic variance in the sea bass (Dicentrarchus labrax). Ecol. Evol. 7(8), 2777-2790. 
Horng, J.L., Chao, P.L., Chen, P.Y., Shih, T.H., Lin, L.Y., 2015. Aquaporin 1 is involved in acid secretion by ionocytes of zebrafish embryos through facilitating $\mathrm{CO}_{2}$ transport. PloS one 10(8), e0136440. Junqueira, L., Bignolas, G., Brentani, R.R., 1979. Picrosirius staining plus polarization microscopy, a specific method for collagen detection in tissue sections. Histochem. J. 11, 447-455.

Kim, G.U., Seo, K.H., Chen, D., 2019. Climate change over the Mediterranean and current destruction of marine ecosystem. Sci. Rep. 9(1), 1-9.

Kim, Y.K., Watanabe, S., Kaneko, T., Huh, M.D. Park, S.I., 2010. Expression of aquaporins 3, 8 and 10 in the intestines of freshwater- and seawater-acclimated Japanese eels Anguilla japonica. Fish. Sci. 76(4), 695-702.

Kinnby, A., Jonsson, P.R., Ortega-Martinez, O., Töpel, M., Pavia, H., Pereyra, R.T., Johannesson, K., 2020. Combining an ecological experiment and a genome scan show idiosyncratic responses to salinity stress in local populations of a seaweed. Front. Mar. Sci. 7, 470.

Köprücü, K., Özdemir, Y., 2005. Apparent digestibility of selected feed ingredients for Nile tilapia (Oreochromis niloticus). Aquaculture 250(1-2), 308-316.

Krahmann, G., Schott, F., 1998. Longterm increases in west rit Mediterranean salinities and temperatures: Anthropogenic and climatic sources. Geophys. Res. Lett. 25 4209-4212.

Largier, J. L., Hollibaugh, J. T., Smith, S. V., 1997. Seasonally ype saline estuaries in Mediterraneanclimate regions. Estuar. Coast. Shelf Sci. 45(6), 789-797.

Larsen, E.H., Møbjerg, N., 2006. $\mathrm{Na}^{+}$recirculation and isosm ${ }^{2}$ ? ?nsport. J. Membr. Biol. 212, 1-15.

Larsen, P.F., Nielsen, E.E., Williams, T.D., Loeschcke, V., ' 008 Intraspecific variation in expression of candidate genes for osmoregulation, heme biosynthesis and st. ss resistance suggests local adaptation in European flounder (Platichthys flesus). Heredity 101(3, , +7-259.

Laverty, G., Skadhauge, E., 2012. Adaptation of tel o $\checkmark t$, very high salinity. Comp. Biochem. Physiol. A $163,1-6$.

Lê, S., Josse, J., Husson, F., 2008. FactoMir $\bullet$ R: an R package for multivariate analysis. J. Stat. Softw. 25(1), 1-18.

Lemaire, C., Versini, J.J., Bonhomme, F., ¿ 7 5. Maintenance of genetic differentiation across a transition zone in the sea: discordance between nuc' $\sim^{r}$ an $d$ cytoplasmic markers. J. Evol. Biol. 18(1), 70-80.

L'Honoré, T., Farcy, E., Blondeau-Bice, Ł., Lorin-Nebel, C., 2020. Inter-individual variability in freshwater tolerance is related to tran $\mathrm{sch}_{1}{ }^{\mathrm{t}}$ level differences in gill and posterior kidney of European sea bass. Gene 741, 144547.

L'Honoré, T., Farcy, E., Chatai \& Gros, R., Ruelle, F., Hermet, S., Blondeau-Bidet, E., Naudet, J., Lorin-Nebel, C., 2019. Are Furop an sea bass as euryhaline as expected? Intraspecific variation in freshwater tolerance. Mar. P': ív (8), 1-16.

Li, Z., Lui, E.Y., Wils. n, 'M. Ip, Y.K., Lin, Q., Lam, T.J. Lam, S.H., 2014. Expression of key ion transporters in the gill nd esophageal-gastrointestinal tract of euryhaline Mozambique tilapia

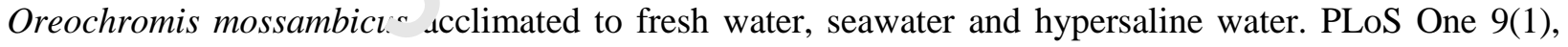
e87591.

Lorin-Nebel, C., Boulo, V., Bodinier, C., Charmantier, G., 2006. The $\mathrm{Na}^{+} / \mathrm{K}^{+} / 2 \mathrm{Cl}^{-}$cotransporter in the sea bass Dicentrarchus labrax during ontogeny: involvement in osmoregulation. J. Exp. Biol. 209(24), 49084922.

Madsen, S.S., Bujak, J., Tipsmark, C.K., 2014. Aquaporin expression in the Japanese medaka (Oryzias latipes) in freshwater and seawater: challenging the paradigm of intestinal water transport? J. Exp. Biol. 217(17), 3108-3121.

Madsen, S.S., Engelund, M.B., Cutler, C.P., 2015. Water transport and functional dynamics of aquaporins in osmoregulatory organs of fishes. Biol. Bull. 229(1), 70-92.

Madsen, S.S., Olesen, J.H., Bedal, K., Engelund, M.B., Velasco-Santamaría, Y.M. Tipsmark, C.K., 2011. Functional characterization of water transport and cellular localization of three aquaporin paralogs in the salmonid intestine. Front. Physiol. 2, 56. 
Madsen, S.S., Weber, C., Nielsen, A.M., Mohiseni, M., Bosssus, M.C., Tipsmark, C.K., 2015. Sexual maturation and changes in water and salt transport components in the kidney and intestine of three-spined stickleback Gasterosteus aculeatus L. Comp. Biochem. Physiol. A 188, 107-119.

Malakpour, S., Coimbra, J., Wilson, J. M., 2018. Osmoregulation in the Plotosidae catfish: Role of the salt secreting dendritic organ. Front. Physiol. 9, 761.

Mariotti, A., 2010. Recent changes in the Mediterranean water cycle: A pathway toward longterm regional hydroclimatic change? J. Clim. 23, 1513-1525.

Martinez, A.S., Cutler, C.P., Wilson, G.D., Phillips, C., Hazon, N., Cramb, G., 2005. Cloning and expression of three aquaporin homologues from the European eel (Anguilla anguilla): effects of seawater acclimation and cortisol treatment on renal expression. Biol. Cell 97, 615-627.

McKenzie, D. J., Zhang, Y., Eliason, E. J., Schulte, P. M., Claireaux, G., Blasco, F. R., Farrell, A. P., 2020. Intraspecific variation in tolerance of warming in fishes. J. Fish Biol. 98(6), 1536-1555.

Metcalfe, N. B., Van Leeuwen, T. E., Killen, S. S., 2016. Does individual variation in metabolic phenotype predict fish behaviour and performance? J. Fish Biol. 88(1), 2, ?-321.

Musch, M.W., Orellana, S.A., Kimberg, L.S., Field, M., Halm, D.R. n'sny, E.J., Frizzell, R.A., 1982. $\mathrm{Na}^{+}-\mathrm{K}^{+}-\mathrm{Cl}^{-}$co-transport in the intestine of a marine teleost. Nature $30\left({ }^{5} 8^{\mathrm{C}} \mathrm{J}\right), 351-353$.

Naciri, M., Lemaire, C., Borsa, P., Bonhomme, F., 1999. Gene c st idy of the Atlantic/Mediterranean transition in sea bass (Dicentrarchus labrax). J. Hered. 90, 591- 496.

Newton, A., Mudge, S.M., 2003. Temperature and salinity Ria Formosa, Portugal. Estuar. Coast. Shelf Sci. 57(1-2), 7325.

Nielsen, C., Madsen, S.S., Björnsson, B.T., 1999. Changf s 1. branchial and intestinal osmoregulatory mechanisms and growth hormone levels during smolti $\mathrm{g}$ o hatchery-reared and wild brown trout. J. Fish Biol. 54, 799-818.

Ostaszewska, T., Korwin-Kossakowski, M., ' ${ }^{1} n_{1}$ ki, J., 2005. Morphological changes of digestive structures in starved tench (Tinca tinca L.) jur 'nil s. Aquacult. Int. 14, 113-126.

Qu, T., Gao, S., Fukumori, I., 2013. Formation of salinity maximum water and its contribution to the overturning circulation in the North Atla tic as revealed by a global general circulation model. J. Geophys. Res. Oceans 118(4), 1982-1994.

Rios, F.S., Kalinin, A.L., Fernandes, M.I J. R intin, F.T., 2004. Changes in gut gross morphology of trara, Hoplias malabaricus (Teleostei, Ery nrı. 'dae) during longterm starvation and after re-feeding. Brazil J. Biol. 64, 683-689.

Rohling, E.J., Bryden, H.L., 19y? Man-induced salinity and temperature increases in Western Mediterranean deep water. J. C`opt, ;s. Res. 97, 11191-11198.

Ruiz-Jarabo, I., González-W _ ^r, ¿.A., Oyarzún, R., Fuentes, J., Poulin, E., Bertrán, C., Vargas-Chacoff, L., 2016. Isolation d. ve dj ergence in osmoregulation in Galaxias maculatus (Jenyns, 1848) (Actinopterygii: Osmerifor. 'es). PLoS One 11(5), e0154766.

Ronkin, D., Seroussi, E., N'tzan, T., Doron-Faigenboim, A., Cnaani, A., 2015. Intestinal transcriptome analysis revealed differential salinity adaptation between two tilapiine species. Comp. Biochem. Physiol. D 13, 35-43.

Samaras, A., Dimitroglou, A., Sarropoulou, E., Papaharisis, L., Kottaras, L., Pavlidis, M., 2016. Repeatability of cortisol stress response in the European sea bass (Dicentrarchus labrax) and transcription differences between individuals with divergent responses. Sci. Rep. 6(1), 1-11.

Santos, C.R.A., Estêvão, M.D., Fuentes, J., Cardoso, J.C.R., Fabra, M., Passos, A.L., Detmers, F.J., Deen, P.M.T., Cerdà, J., Power, D.M., 2004. Isolation of a novel aquaglyceroporin from a marine teleost (Sparus auratus): function and tissue distribution. J. Exp. Biol. 207, 1217-1227.

Sardella, B.A., Brauner, C.J., 2008. The effect of elevated salinity on 'California' Mozambique tilapia (Oreochromis mossambicus x O. urolepis hornorum) metabolism. Comp. Biochem. Physiol. C 148(4), 430-436.

Sardella, B.A., McCormick, S.D., Regish, A.M. Christensen, A.K., 2009. Distinct freshwater and seawater isoforms of NKA in gill chloride cells of Atlantic salmon. J. Exp. Biol. 212(24), 3994. 
Schauer, K.L., Reddam, A., Xu, E.G., Wolfe, L.M., Grosell, M., 2018. Interrogation of the Gulf toadfish intestinal proteome response to hypersalinity exposure provides insights into osmoregulatory mechanisms and regulation of carbonate mineral precipitation. Comp. Biochem. Physiol. D 27, 66-76.

Scott, G.R., Rogers, J.T., Richards, J.G., Wood, C.M., Schulte, P.M., 2004. Intraspecific divergence of ionoregulatory physiology in the euryhaline teleost Fundulus heteroclitus: possible mechanisms of freshwater adaptation. J. Exp. Biol. 207(19), 3399-3410.

Shephard, K.L., 1994. Functions for fish mucus. Rev. Fish Biol. Fish. 4, 401-429.

Skadhauge, E., 1974. Coupling of transmural flows of $\mathrm{NaCl}$ and water in the intestine of the eel (Anguilla anguilla). J. Exp. Biol. 60(2), 535-546.

Stitt, B. C., Burness, G., Burgomaster, K. A., Currie, S., McDermid, J. L., Wilson, C. C., 2014. Intraspecific variation in thermal tolerance and acclimation capacity in brook trout (Salvelinus fontinalis): physiological implications for climate change. Physiol. Biochem. Zool. 87(1), 15-29.

Sunde, J., Tamario, C., Tibblin, P., Larsson, P., Forsman, A., 2019. Variation in salinity tolerance between and within anadromous subpopulations of pike (Esox lucius). Sc. Rep. 8(1), 1-11.

Sundell, K., Sundh, H., 2012. Intestinal fluid absorption in anadrom sus saımonids: importance of tight junctions and aquaporins. Front. Physiol. 3, 388.

Tingaud-Sequeira, A., Chauvigné, F., Fabra, M., Lozano, J., Ral úa, J., Cerdà, J., 2008. Structural and functional divergence of two fish aquaporin-1 water channels f $10 v,$. g teleost-specific gene duplication. BMC Evol. Biol. 8, 259.

Tingaud-Sequeira, A., Calusinska, M., Finn, R.N., Chau igné F., Lozano, J., Cerdà, J., 2010. The zebrafish genome encodes the largest vertebrate repertoire of 'inctional aquaporins with dual paralogy and substrate specificities similar to mammals. BMC F vo . Biol. 10(1), 1-18.

Tipsmark, C.K., Sørensen, K.J., Madsen, S.S., 201C. \& Iu porin expression dynamics in osmoregulatory tissues of Atlantic salmon during smoltification _. I s awater acclimation. J. Exp. Biol. 213(3), 368-379.

Tram, N.D.Q., Ngoan, L.D., Hung, L.T., L: רdb rg, J.E., 2011. A comparative study on the apparent digestibility of selected feedstuffs in hybrid ca. "ish (Clarias macrocephalus $\times$ Clarias gariepinus) and Nile tilapia (Oreochromis niloticus). Aquac. Nutr. 17(2), e636-e643.

Tran-Ngoc, K.T., Schrama, J.W., Le, M\%. Ns xyen, T.H., Roem, A J., Verreth, J.A., 2017. Salinity and diet composition affect digestibility snd intestinal morphology in Nile tilapia (Oreochromis niloticus). Aquaculture 469, 36-43.

Vandeputte, M., Gagnaire, P.A., A laı, F., 2019. The European sea bass: a key marine fish model in the wild and in aquaculture. Anim. Canc 50(3), 195-206.

Vandesompele, J., De Preter, Y., F، tyn, F., Poppe, B., Van Roy, N., De Paepe, A., Speleman, F., 2002. Accurate normalization of $\cdots$-inne quantitative RT-PCR data by geometric averaging of multiple internal control genes. C`nc ne liol. 3(7), Research0034.

Varsamos, S., Bonga, S.W., Charmantier, G., Flik, G., 2004. Drinking and $\mathrm{Na}^{+} / \mathrm{K}^{+}$ATPase activity during early development of $\mathrm{El}$ " pean sea bass, Dicentrarchus labrax: ontogeny and short-term regulation following acute salinity changes. J. Exp. Mar. Biol. Ecol. 311(2), 189-200.

Varsamos, S., Diaz, J., Charmantier, G., Blasco, C., Connes, R., Flik, G., 2002. Location and morphology of chloride cells during the post-embryonic development of the European sea bass, Dicentrarchus labrax. Anat. Embryol. 205(3), 203-213.

Veillette, P.A., White, R.J., Specker, J.L., 1993. Changes in intestinal fluid transport in Atlantic salmon (Salmo salar L) during parr-smolt transformation. Fish Physiol. Biochem. 12, 193-202.

Watanabe, S., Mekuchi, M., Ideuchi, H., Kim, Y.K., Kaneko, T., 2011. Electroneutral cation-Cl ${ }^{-}$ cotransporters NKCC2 beta and NCCbeta expressed in the intestinal tract of Japanese eel Anguilla japonica. Comp. Biochem. Physiol. A 159, 427-435.

Wood, C.M., Bucking, C., 2011. The role of feeding in salt and water balance. In: Grosell M, Farrell AP, Brauner CJ, editors. The Multifunctional Gut of Fish. Fish Physiology, vol. 30. San Diego: Academic Press $165-212$.

Wood, C.M., Grosell, M., 2012. Independence of net water flux from paracellular permeability in the intestine of Fundulus heteroclitus, a euryhaline teleost. J. Exp. Biol. 215(Pt 3), 508-517. 
Yilmaz, H.A., Turkmen, S., Kumlu, M., Eroldogan, O.T., Perker, N., 2020. Alteration of growth and temperature tolerance of European sea bass (Dicentrarchus labrax linnaeus 1758) in different temperature and salinity combinations. Turk. J. Fish. Aquat. Sci. 20(5), 331-340.

Yuan, X., Yang, H.,Wang, L., Zhou, Y., Gabr, H.R., 2010. Effects of salinity on energy budget in pondcultured sea cucumber Apostichopus japonicus (Selenka) (Echinodermata: Holothuroidea). Aquaculture 306, 348-351.

Zhou, Q.C., Yue, Y.R., 2012. Apparent digestibility coefficients of selected feed ingredients for juvenile hybrid tilapia, Oreochromis niloticus× Oreochromis aureus. Aquac. Res. 43(6), 806-814.

Figure legends :

Fig. 1. Posterior intestine (A, B, C, D) sections of Mediterrar ean (A, B) and Atlantic (C, D) European sea bass maintained in seawater $(\mathrm{SW})(\mathrm{A}, \mathrm{C})$ and $\mathrm{r}$ y $\mathrm{r}$ rsaline water (HW) (B, D). Cell perimeter and area of enterocytes in posterior intestine are $\mathrm{e}_{\mathrm{r}}{ }^{\text {-er }}$ ented in three fish per condition (E-F). Measurements from a same animal are indicated $h_{r}$ a same color. Data are represented as the mean +/-SD. Different letters denote significar: dit erences between groups (two-way ANOVA followed by Tukey's multiple comparisons te $i, i<0.05, \mathrm{~N}=8$ ). Scale bars: $50 \mu \mathrm{m}$.

Fig. 2. NKA activity (A) in the anterior (AI) anc $\mathrm{p}^{\text {t }}$ _rior intestine (PI) and relative $n k a \alpha 1 a(\mathrm{~B})$ and $n k c c 2$ (C) mRNA expression were me'su ed ' $\eta$ the posterior intestine of Mediterranean (M) and Atlantic (A) European sea bass mainu' ${ }^{i r}$ ed in seawater (SW) and hypersaline water (HW). Different letters denote significant differences between groups (two-way $(B, C)$ and three-way (A) ANOVA followed by Tukey's test $i<0.05, \mathrm{~N}=12$ ). Data are represented as the median, first and third quartile (box), minimun an maximum values.

Fig. 3. Immunoblots probed $w^{i}$ th a polyclonal antibody raised against aquaporin $8 \mathrm{ab}$ subunit (AQP8ab). The marker (Ma) is indicated on the left of the immunoblot (kDa) (A). Relative AQP8ab abundance (A) and relaive $a q p 8 a b$ (B), aqp8aa (C), aqp8b (D) mRNA expression were

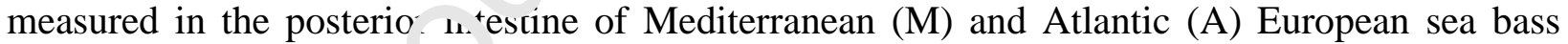
maintained in seawate $\left({ }^{\wedge} \mathrm{W}\right)$ and hypersaline water $(\mathrm{HW})$. Different letters denote significant differences between grou, s (two-way ANOVA followed by Tukey's test, $P<0.05, \mathrm{~N}=9$ for protein expression and $\mathrm{v}=12$ for mRNA expression). Data are represented as the median, first and third quartile (box), minimum and maximum values.

Fig. 4. Relative aqp $1 a$ (A), aqp $1 b$ (B) and $a q p 10 b(\mathrm{C})$ mRNA expression in the posterior intestines of Mediterranean (M) and Atlantic (A) European sea bass maintained in seawater (SW) and hypersaline water (HW). Different letters denote significant differences between groups (two-way ANOVA followed by Tukey's test, $P<0.05, \mathrm{~N}=12$ ). Data are represented as the median, first and third quartile (box), minimum and maximum values.

Fig. 5. Loading plot of principal component analysis (PCA) representing measured variables (A) and the individuals (B) based on NKA activity, nkaala, aqp8ab, aqp8aa, nkcc2, aqp10b, aqp8b, $a q p 10 b$, aqpla and $a q p 1 b$ gene expressions and comparing 4 conditions (Mediterranean (M) and Atlantic (A) European sea bass maintained in seawater (SW) and hypersaline water (HW) in the 
(Dim1 $\times$ Dim2) coordination plane. Orange and green colors in A respectively represent strong and weak $\cos ^{2}$ values. Ellipses in B group D. labrax from the four conditions (MSW in blue, MHW in red, ASW in yellow and AHW in green).

Fig. 6. Immunofluorescent staining of AQP8ab (Aquaporin 8ab; green) (A, B, C, D), NKA $\alpha$ $\left(\mathrm{Na}^{+} / \mathrm{K}^{+}\right.$-ATPase $\alpha$; red) (A) and $\mathrm{T} 4$ (recognizes $\mathrm{Na}-\mathrm{K}-\mathrm{Cl}$ cotransporter 2 and $\mathrm{Na}^{+} / \mathrm{Cl}^{-}$ cotransporter; fuchsia) (C) in anterior intestine of Mediterranean European sea bass maintained in seawater (MSW, A, B, C, D). A and B are merged images as well as C+D. Scales: $40 \mu \mathrm{m}$ (A, B), $10 \mu \mathrm{m}(\mathrm{C}, \mathrm{D})$.

Fig. 7. Immunofluorescent staining of AQP8ab (Aquaporin 8ab; green) (A, B, C, D, E, F), NKA $\alpha\left(\mathrm{Na}^{+} / \mathrm{K}^{+}\right.$-ATPase $\alpha$; red) (D) and T4 (recognizes Na-K-Cl cotransporter 2 and $\mathrm{Na}^{+} / \mathrm{Cl}^{-}$ cotransporter; fuchsia) (A, B, E) in posterior intestine of Mediterran ` ₹n (A, D, E, F) and Atlantic $(B, C)$ sea bass maintained in seawater. $B$ and $C$ are merged im tges as well as E+F. Scales: 100 $\mu \mathrm{m}$ (A, D), $20 \mu \mathrm{m}$ (B, C, E, F).

Supplementary figures : 
Legends of the tables :

Table 1: Primer sequences used for qPCR in this study. F: forward primer; R: reverse primer. Sequences ID indicates gene sequences from the European sea bass genome or Genbank identification numbers when available.

Table 2: Cell perimeter and area of enterocytes are represented in Mediterranean (M) and Atlantic (A) European sea bass maintained in seawater (SW) and hypersaline water (HW). Different letters denote significant differences between groups (two-way Anova followed by Tukey's test, $P<0.05$, means $\pm \mathrm{SD}, \mathrm{N}=8$ ). 
A

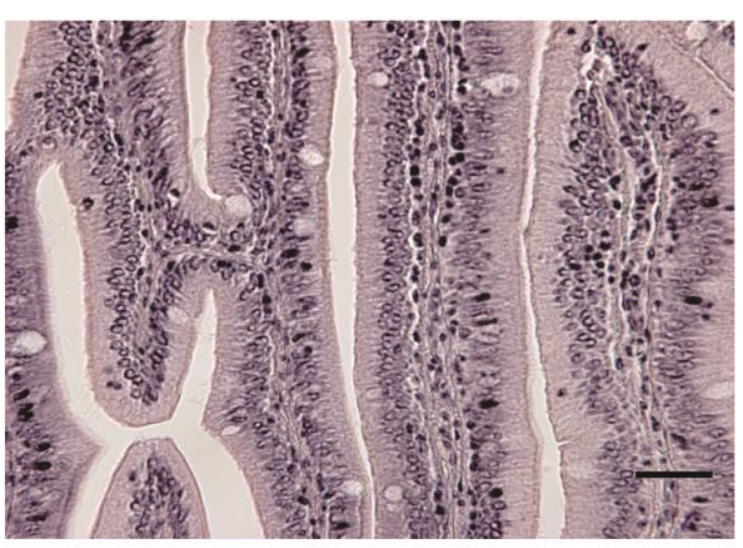

C

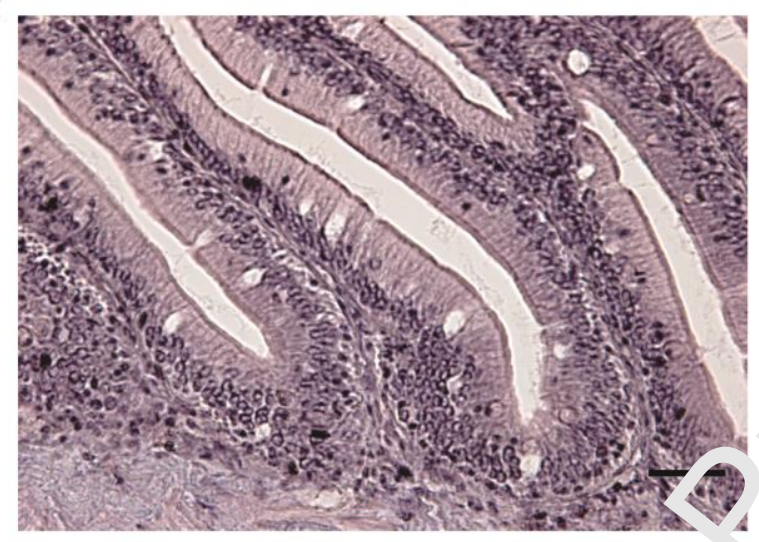

$\mathbf{E}$

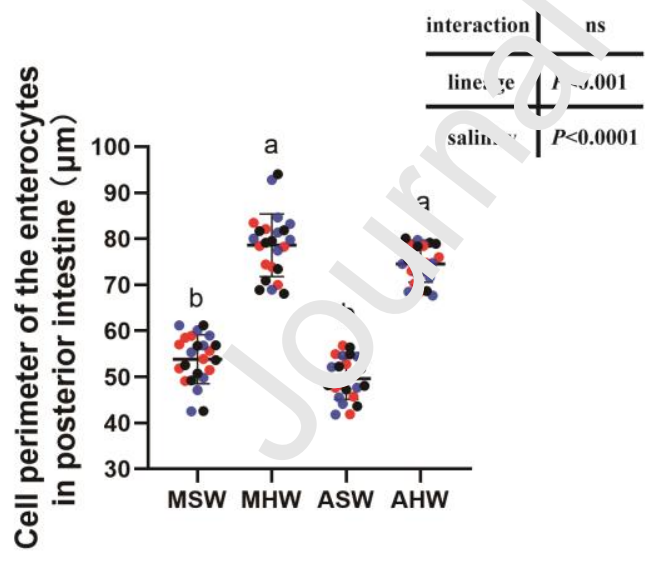

Fig. 1
B

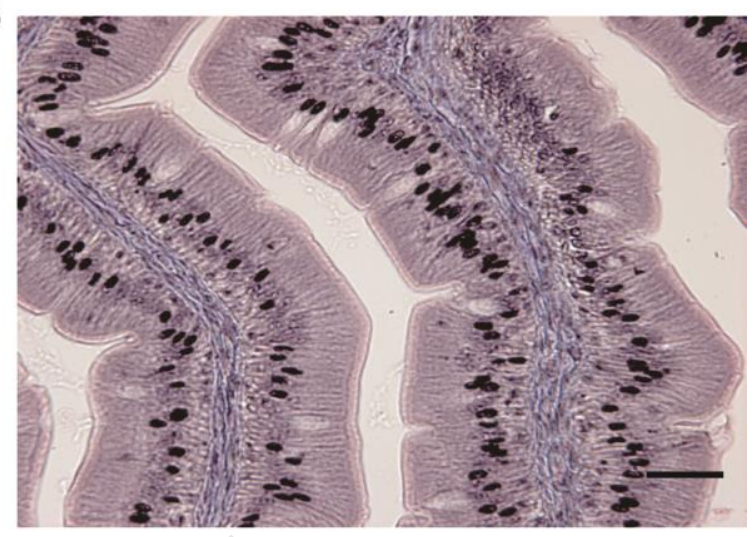

D

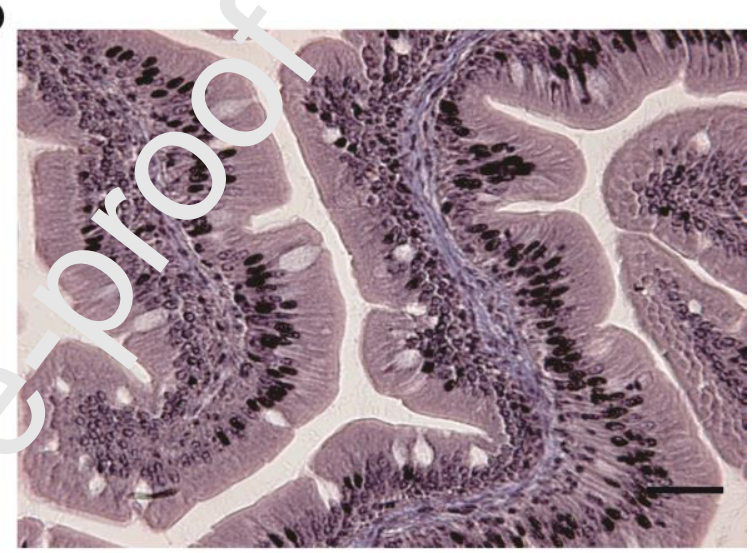

F

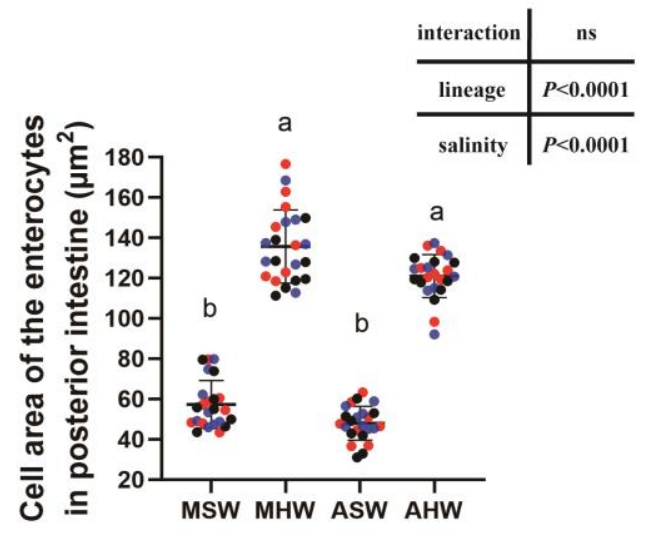


A
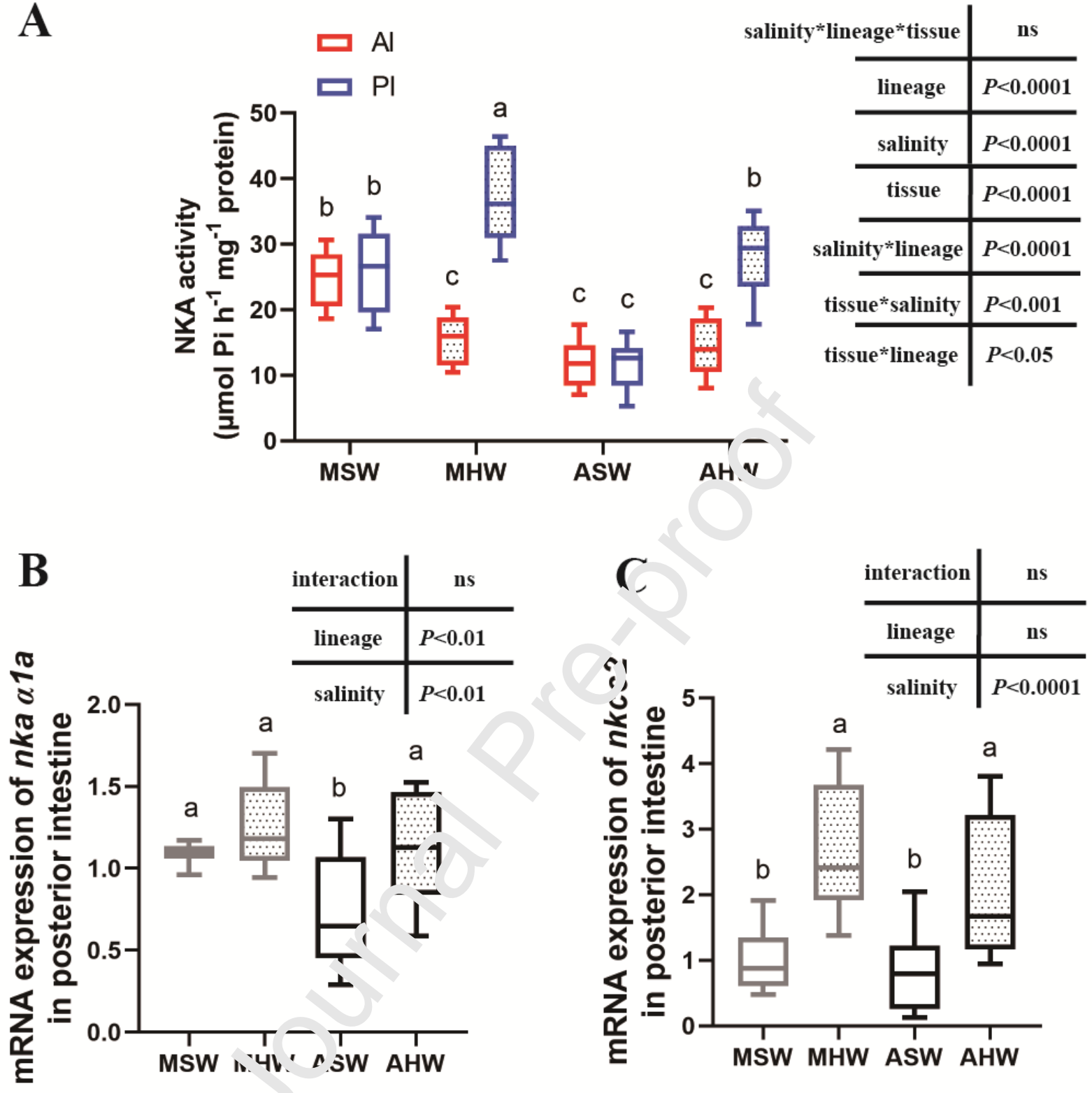

Fig. 2 
A

Ma MSW MHW ASW AHW

27
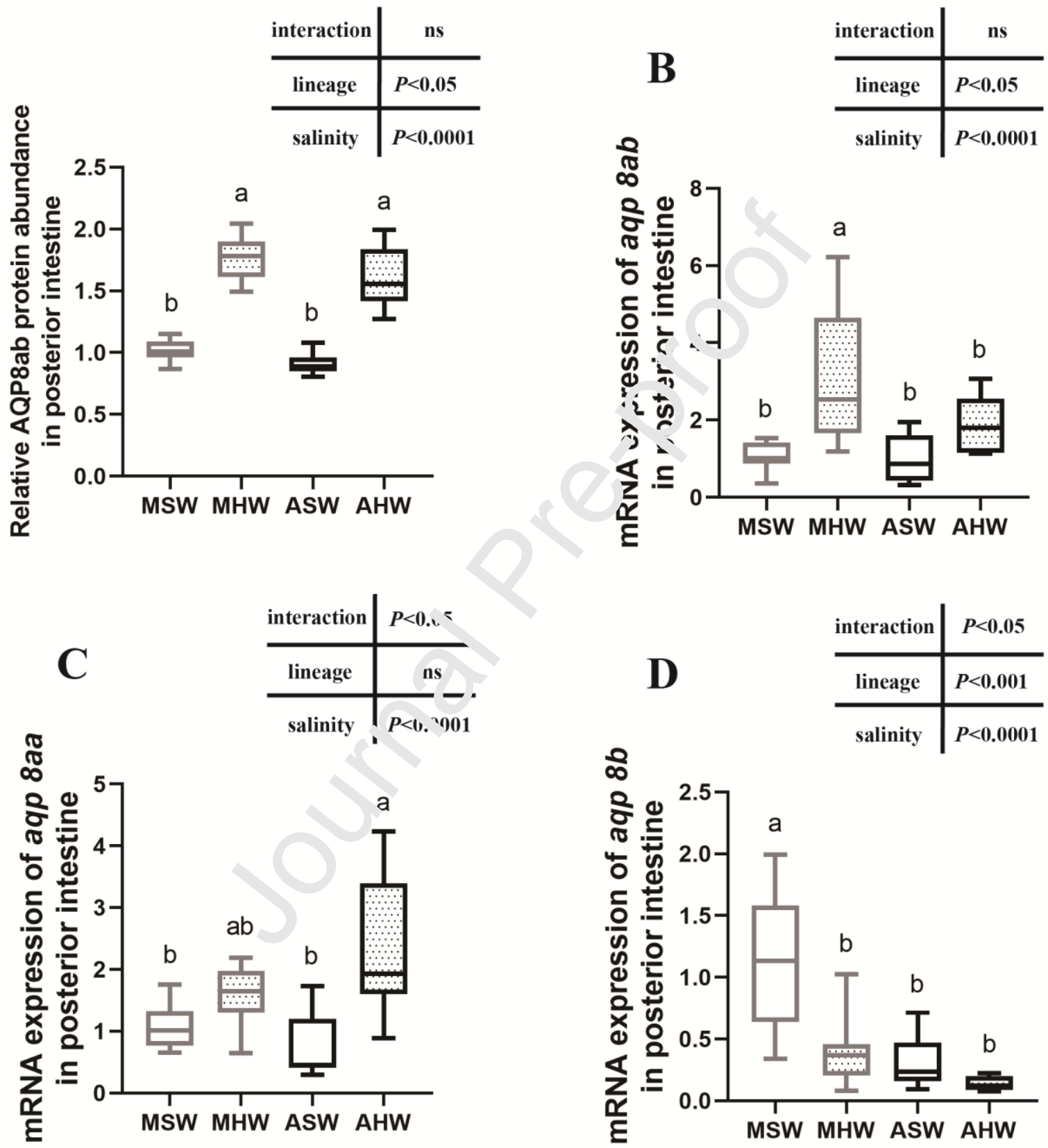

Fig. 3 


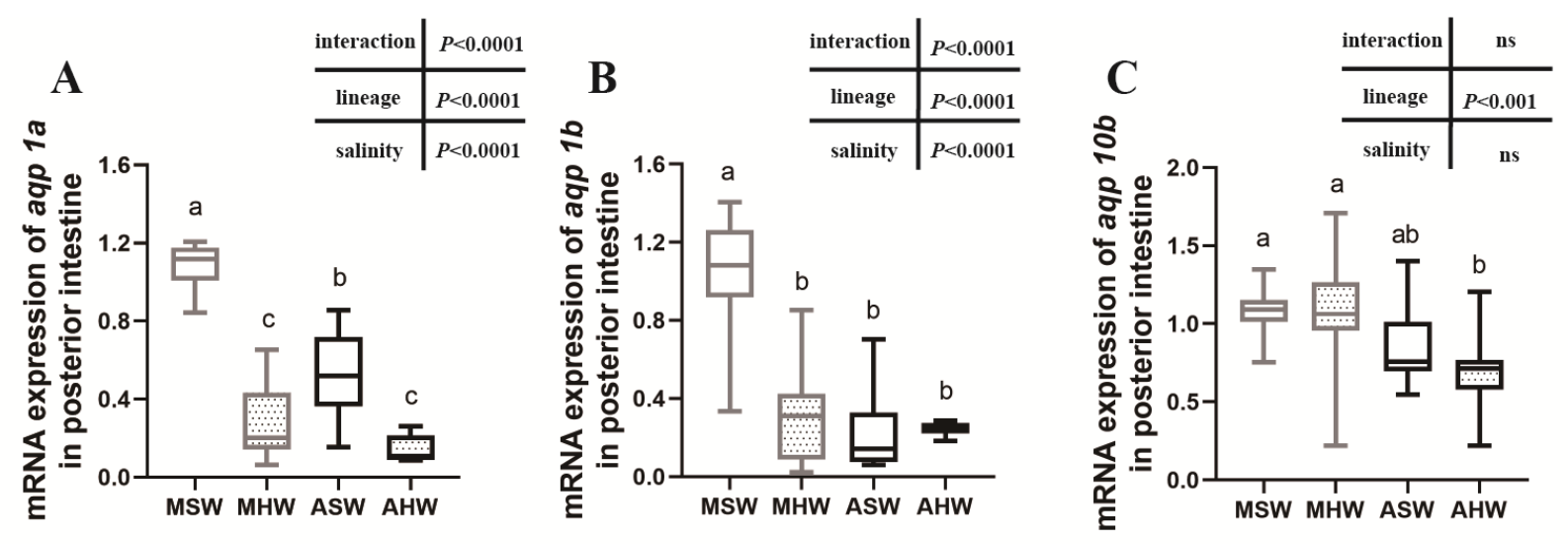

Fig. 4 


\section{Journal Pre-proof}

A

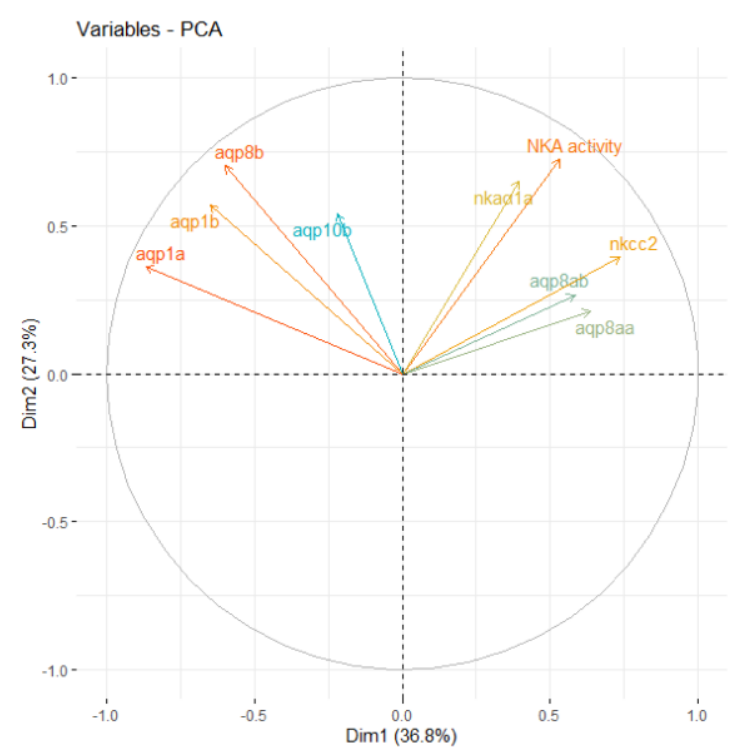

Fig. 5 


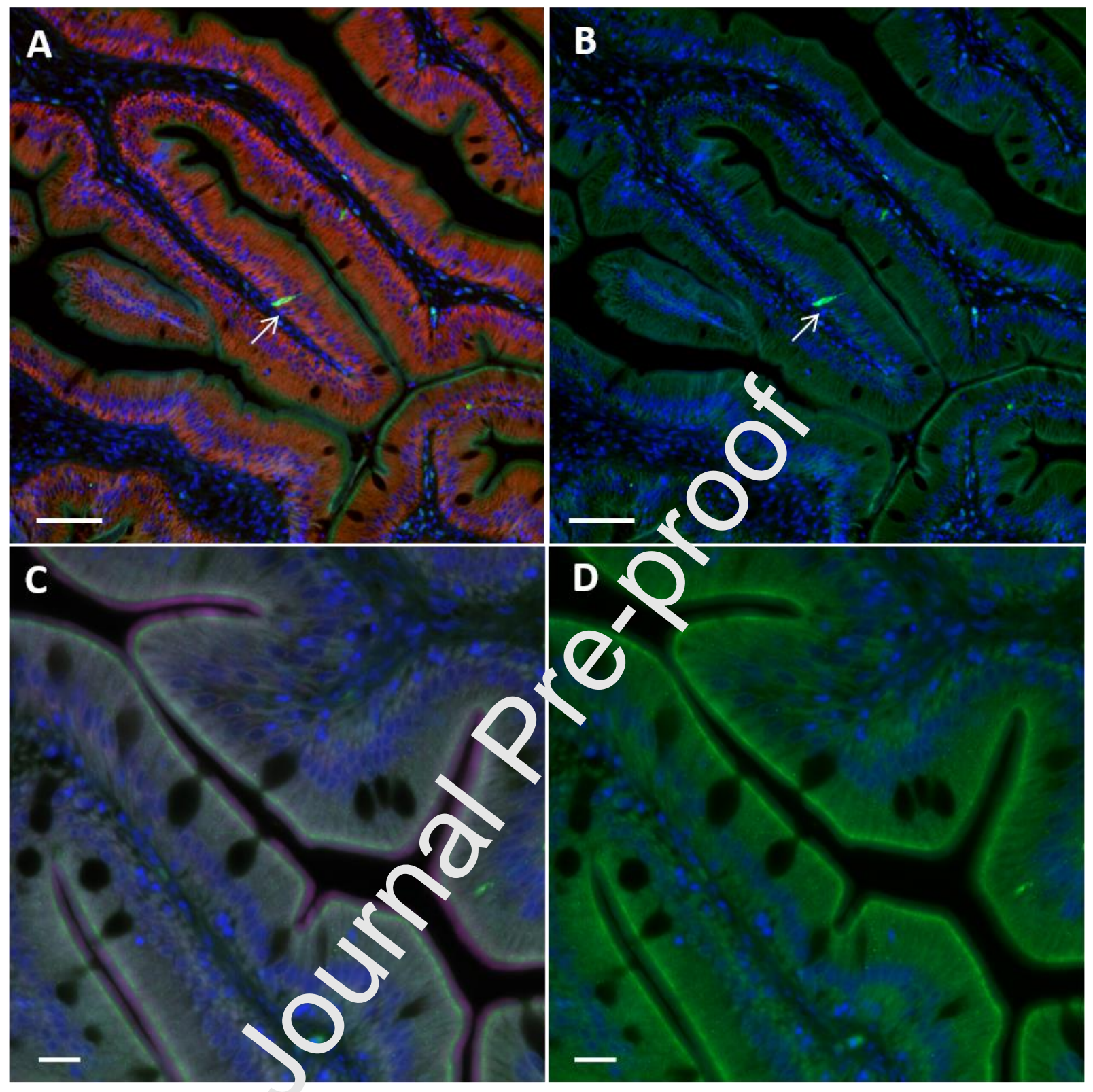

Fig. 6 


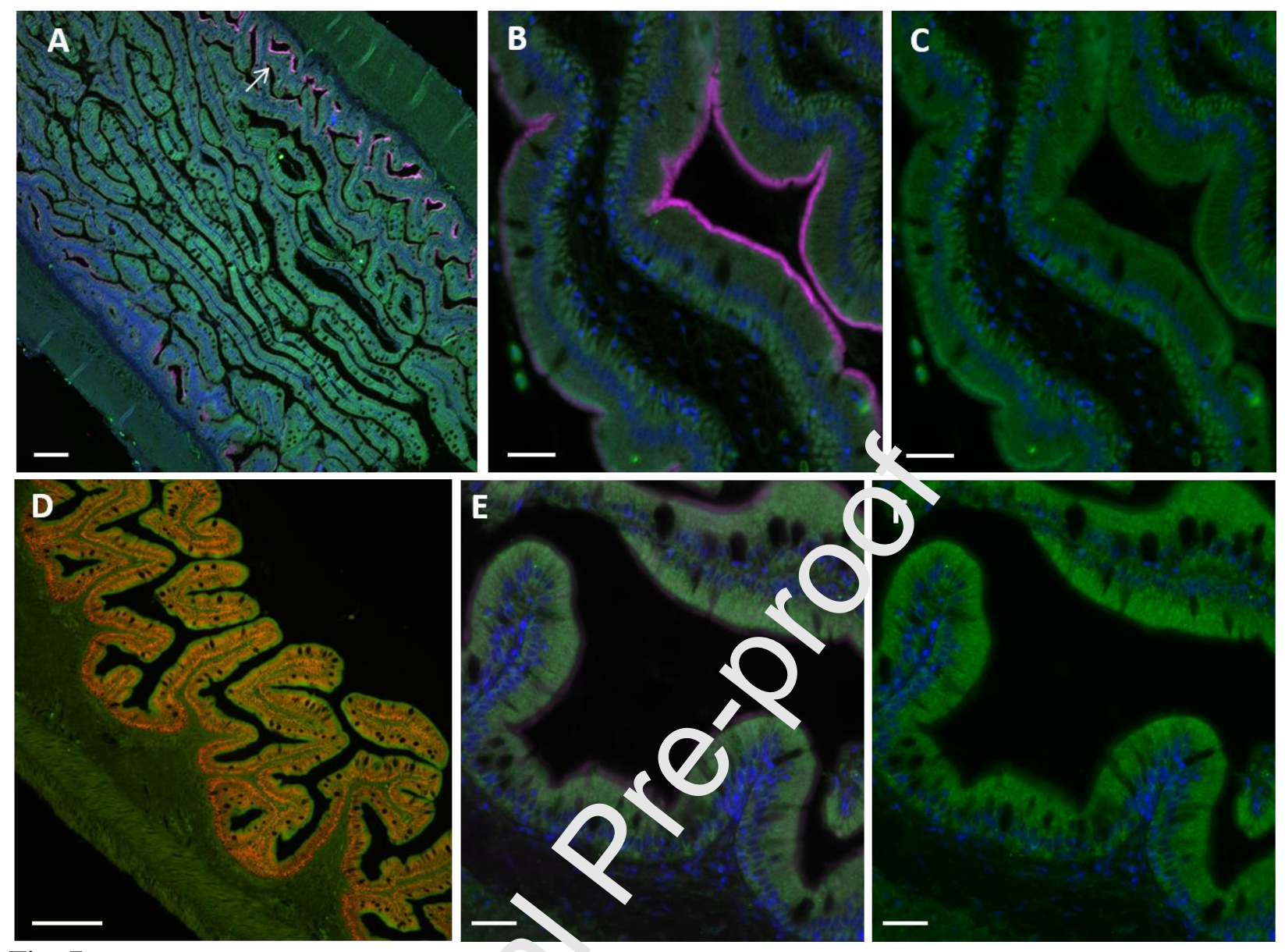

Fig. 7 
Table 1 Primer sequences used for qPCR in this study. F: forward primer; R: reverse primer. Sequences ID indicates gene sequences from the European sea bass genome or Genbank identification numbers when available.

\begin{tabular}{|c|c|c|c|c|c|}
\hline Sequences ID & $\begin{array}{l}\text { Target } \\
\text { gene }\end{array}$ & $\begin{array}{l}\text { Primer } \\
\text { name }\end{array}$ & Sequence (from $5^{\prime}$ to $3^{\prime}$ ) & $\begin{array}{l}\text { Amplicon } \\
\text { Size }\end{array}$ & Efficiency \\
\hline KP400258 & nka $\alpha 1 a$ & $\begin{array}{l}n k a \alpha 1 a-\mathrm{F} \\
n k a \alpha 1 a-\mathrm{R}\end{array}$ & $\begin{array}{l}\text { CCTCAGATGGCAAGGAGAAG } \\
\text { CCCTGCTGAGATCGGTTCC }\end{array}$ & 146 & 2.035 \\
\hline KP400259 & $n k a \alpha 1 b$ & $\begin{array}{l}n k a \alpha 1 b-\mathrm{F} \\
n k a \alpha 1 b-\mathrm{R}\end{array}$ & $\begin{array}{l}\text { AGCAGGGCATGAAGAACAAG } \\
\text { CCTGGGCTGCGTCTGAGG }\end{array}$ & 204 & 2.119 \\
\hline DLAgn_00006940 & aqp $1 a$ & $\begin{array}{l}\text { aqp } 1 a-\mathrm{F} \\
a q p 1 a-\mathrm{R}\end{array}$ & $\begin{array}{l}\text { CTGCCTGGGACACTTGGCAGC } \\
\text { TCTCAGGGAAGTCATCAAA }\end{array}$ & 194 & 2.183 \\
\hline DLAgn_00006960 & $a q p 1 b$ & $\begin{array}{l}a q p 1 b-\mathrm{F} \\
a q p 1 b-\mathrm{R}\end{array}$ & $\begin{array}{l}\text { CGGACCAGCCGTGATACAGG } \\
\text { AGCAGGACGTTCCAGCCCG }\end{array}$ & 147 & 1.936 \\
\hline DLAgn_00099310 & aqp $8 a a$ & $\begin{array}{l}\text { aqp } 8 a a-\mathrm{F} \\
\text { aqp } 8 a a-\mathrm{R}\end{array}$ & $\begin{array}{l}\text { TGCTTCCTTTGGCGGTGCC } \\
\text { CAACATCCCTCCAGCAAGT }\end{array}$ & 199 & 2.110 \\
\hline DLAgn_00099320 & $a q p 8 a b$ & $\begin{array}{l}a q p 8 a b-\mathrm{F} \\
a q p 8 a b-\mathrm{R}\end{array}$ & $\begin{array}{l}\text { AGCCGCCTGTGTCCAAACCTCC } \\
\text { CATAACCGCCACCATCACTG }\end{array}$ & 198 & 1.808 \\
\hline DLAgn_00189570 & $a q p 8 b$ & $\begin{array}{l}a q p \quad 8 b-\mathrm{F} \\
a q p 8 b-\mathrm{R}\end{array}$ & $\begin{array}{l}\text { TGTCAGTTGGTCGGAGGAGTC } ~ \\
\text { CAGACAAGTGCCAGATA }: 11\end{array}$ & 282 & 2.024 \\
\hline DLAgn_00202560 & aqp $10 b$ & $\begin{array}{l}\text { aqp } 10 b-\mathrm{F} \\
\text { aqp } 10 b-\mathrm{R}\end{array}$ & $\begin{array}{l}\text { AGCGGCTACGCACTTAAC } \\
\text { CAGTGTTCCCAACAG } \text {;Cl }\end{array}$ & 150 & 1.811 \\
\hline FM004681 & fau & $\begin{array}{l}f a u-\mathrm{F} \\
f a u-\mathrm{R}\end{array}$ & $\begin{array}{l}\text { GACACCCAAGGTTGAC } \_1 \text { GCAG } \\
\text { GGCATTGAAGCAC } 1 \text { TA } ₫ \text { GAGTTG }\end{array}$ & 150 & 1.851 \\
\hline AJ866727 & $e f 1 \alpha$ & $\begin{array}{l}\text { efl } \alpha-\mathrm{F} \\
\text { efl } \alpha-\mathrm{R}\end{array}$ & 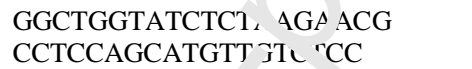 & 239 & 1.853 \\
\hline DLAgn_00023060 & $l 13$ & $\begin{array}{l}l 13-\mathrm{F} \\
l 13-\mathrm{R}\end{array}$ & $\begin{array}{l}\text { TCTGGAGGA }{ }^{\top} \mathrm{T} \text { ICAGGGGCATGC } \\
\text { AGACGCAC } \triangle A^{\prime}, C \text { TTGAGAGCAG }\end{array}$ & 148 & 1.873 \\
\hline
\end{tabular}


Table 2 Cell perimeter and area of enterocytes are represented in Mediterranean (M) and Atlantic (A) European sea bass maintained in seawater (SW) and hypersaline water (HW). Different letters denote significant differences between groups (two-way Anova followed by Tukey's test,

$$
P<0.05 \text {, means } \pm \mathrm{SD}, \mathrm{N}=8 \text { ). }
$$

\begin{tabular}{lcc}
\hline Conditions & Cell perimeter $(\mu \mathrm{m})$ & Cell area $\left(\mu \mathrm{m}^{2}\right)$ \\
\hline \multicolumn{2}{l}{ Anterior intestine } & \\
MSW & $49.18 \pm 4.28^{\mathrm{b}}$ & $63.64 \pm 6.97^{\mathrm{b}}$ \\
MHW & $61.52 \pm 4.82^{\mathrm{a}}$ & $114.62 \pm 17.24^{\mathrm{a}}$ \\
ASW & $46.11 \pm 6.13^{\mathrm{b}}$ & $57.64 \pm 13.42^{\mathrm{b}}$ \\
AHW & $64.51 \pm 4.98^{\mathrm{a}}$ & $128.38 \pm 19.59^{\mathrm{a}}$ \\
Posterior intestine & \\
MSW & $53.83 \pm 5.30^{\mathrm{b}}$ & $57.32 \pm 1.9^{\mathrm{b}}$ \\
MHW & $78.60 \pm 6.80^{\mathrm{a}}$ & $136.6 \mathrm{\alpha}+2 \mathrm{n} 1^{\mathrm{a}}$ \\
ASW & $49.64 \pm 4.52^{\mathrm{b}}$ & $47.29 \pm .41^{\mathrm{b}}$ \\
AHW & $74.54 \pm 3.95^{\mathrm{a}}$ & $12.99 \pm 10.71^{\mathrm{a}}$ \\
\hline
\end{tabular}




\section{Credit author statement}

Quanquan Cao : Investigation, Methodology, Writing-Original draft, Formal analysis, Visualization Eva Blondeau-Bidet : Investigation, Software, Visualization

Catherine Lorin-Nebel : Conceptualization, Methodology, Resources, Writing-Review and Editing, Visualization, Validation, Supervision 


\section{Declaration of interests}

$\bigotimes$ The authors declare that they have no known competing financial interests or personal relationships that could have appeared to influence the work reported in this paper.

$\square$ The authors declare the following financial interests/personal relationships which may be considered as potential competing interests: 


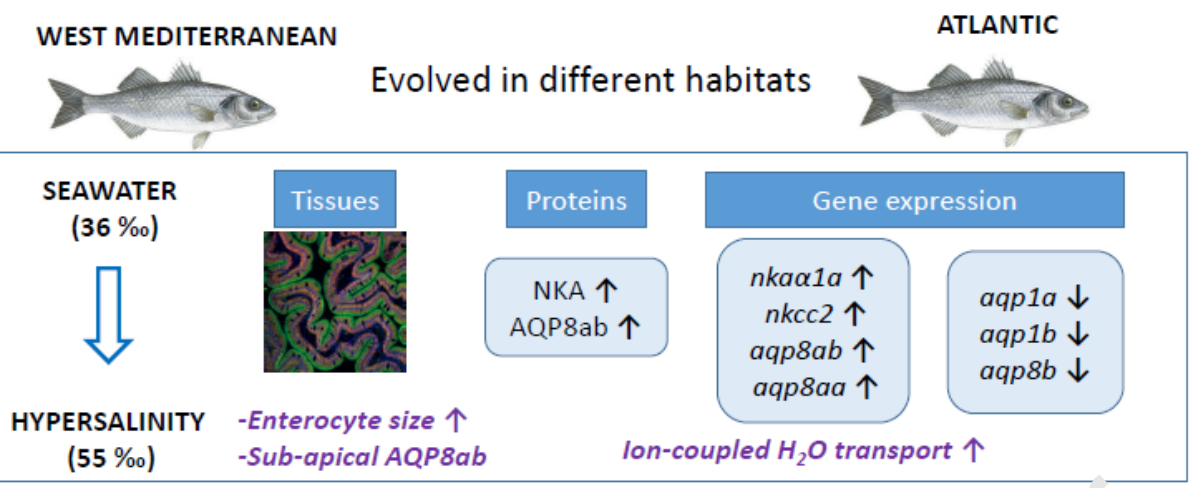

Intraspecific variability in physiological mechanisms ?

NKA \& AQP1 higher in

Yes, in SEAWATER notably

Mediterranean

Graphical abstract 
Highlights

- D. labrax successfully respond to hypersalinity at the posterior intestinal level

- Intestinal aquaporin 8ab and 8aa are overexpressed in response to hypersalinity

- Solute-coupled ion transport is characterized at posterior intestinal level

- Intraspecific differences were measured between Atlantic and Mediterranean D. labrax 